July 2004/30

\section{Issues paper}

This report is for information
This report describes research to establish the range and types of international student mobility available to UK students and to ascertain current trends. The report analyses published statistics for scheme-led mobility programmes, the arrangements at UK higher education institutions for both scheme-led and other international mobility programmes, and attitudes to mobility among students and staff.

\title{
International student mobility
}

Report by the Sussex Centre for Migration Research, University of Sussex, and the Centre for Applied Population Research, University of Dundee

Commissioned by HEFCE, SHEFC, HEFCW, DEL, DfES, UK Socrates Erasmus Council, HEURO, BUTEX and the British Council 


\section{Contents}

Acknowledgements 2

Scope of report and recommendations from the steering group 3

Executive summary 6

1. Context, aims and organisation of the study 9

1.1 Context of the study 9

$\begin{array}{ll}1.2 \text { Eight key questions } & 10\end{array}$

$\begin{array}{ll}1.3 \text { Organisation of the research } & 10\end{array}$

1.4 Definition of international student mobility 11

2. The national and international statistical picture 12

2.1 International trends and comparisons: where the UK fits in 12

2.2 Erasmus mobility 13

2.3 Other national and internationally managed mobility schemes 16

2.4 Student mobility outside the Socrates-Erasmus programme 18

3. The institutional perspective 21

3.1 Managing mobility 21

3.1.1 Administering mobility 21

3.1.2 Strategies and tensions $\quad 22$

3.1.3 Departmental perspectives: priorities and imbalances 23

3.1.4 Rationalising exchanges, reorienting mobility 25

3.1.5 Work placements and field trips 26

$\begin{array}{ll}3.1 .6 & \text { Other issues } \\ \end{array}$

3.2 Drivers and barriers - staff views $\quad 27$

\begin{tabular}{ll}
3.2 .1 & Benefits of mobility \\
\hline
\end{tabular}

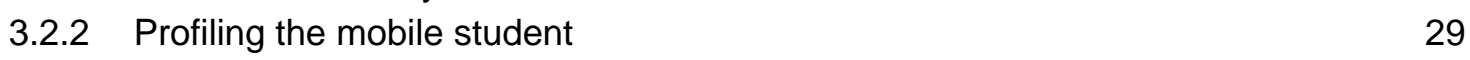

$\begin{array}{lll}3.2 .3 & \text { Deterring factors } & 31\end{array}$

3.2.4 Concluding points 33

4. The student perspective $\quad 34$

4.1 Movers and non-movers $\quad 34$

4.2 Perceived benefits and problems associated with mobility 36

$\begin{array}{ll}4.3 \text { Drivers and barriers to international student mobility } & 37\end{array}$

$\begin{array}{lll}\text { 4.3.1 Financial factors } & 37\end{array}$

$\begin{array}{ll}\text { 4.3.2 Language factors } & 39\end{array}$

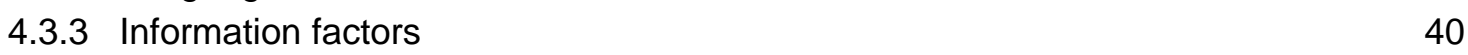

4.3.4 Attitudinal and socio-cultural factors $\quad 40$

4.4 Further comparisons $\quad 41$

4.5 A model for student mobility 41

4.6 Future mobility 42

5. Synthesis and implications of findings $\quad 45$

5.1 The eight questions answered 45

$\begin{array}{ll}5.2 \text { Policy implications } & 47\end{array}$ 


\section{Annexes}

$\begin{array}{lll}\text { Annex A What the literature tells us about international student mobility } & 49\end{array}$

$\begin{array}{lll}\text { Annex B } & \text { Research methods } & 51\end{array}$

$\begin{array}{lll}\text { Annex C Supplementary tables for international student mobility } & 74\end{array}$

Annex D Statistical analysis of the HESA-Erasmus matched dataset 81

$\begin{array}{lll}\text { Annex E The HEl questionnaire: supplementary tables } & 91\end{array}$

Annex F Mobility initiatives in Northern Ireland $\quad 95$

Annex G Promotion of mobility on HEl web-sites $\quad 99$

$\begin{array}{lll}\text { Annex } \mathrm{H} & \text { Staff interviews speaking about language and mobility } & 101\end{array}$

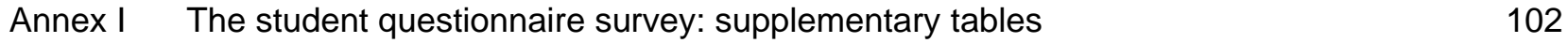

$\begin{array}{lll}\text { Annex J } & \text { References } & 112\end{array}$

$\begin{array}{lll}\text { Annex K } & \text { List of acronyms } & 114\end{array}$

$\begin{array}{lll}\text { Annex } L \quad \text { List of sponsors and steering group members } & 115\end{array}$

\section{Acknowledgements}

Throughout this study the consultants have been greatly helped by the encouragement and advice of members of the advisory and steering groups. We have especially appreciated the support of Jannette Cheong and Beth Steiner at the Higher Education Funding Council for England (HEFCE). The expertise of John Reilly (UK Socrates-Erasmus Council), John Thompson and Mark Gittoes (HEFCE), Judy Powell and Barrie Morgan (British Council), Beatrice Merrick (UKCOSA), Annette Kratz (British Universities Transatlantic Exchange Association, BUTEX) and Adrian Hawksworth (Association of UK Higher Education European Officers, HEURO) was invaluable. We acknowledge the excellent administrative back-up of Rachel Titman at HEFCE and Jenny Money and Mark Thompson at Sussex. Finally, we are grateful to all the students and staff in HEls across the UK who gave generously of their time to help us in the surveys.

HEFCE would like to thank those members of the steering group who gave generously of their time to work closely with the consultants as the study progressed: Judy Powell and Dr Barrie Morgan of the British Council, Dr Annette Kratz of Keele University, Dr Beatrice Merrick of UKCOSA, John Reilly of the UK Socrates-Erasmus Council, and the many others who commented, advised or made available data to the team.

The sponsors and steering group would like to acknowledge the work of the Sussex Centre for Migration Research at the University of Sussex and the Centre for Applied Population Research at the University of Dundee in undertaking this study. The knowledge and commitment of Professors King and Findlay to the work has been impressive, and the steering group appreciated their willingness to discuss openly many complex issues, as the study progressed. The dedication of the whole team to the undertaking was evident throughout, and the sponsors are particularly grateful for the enthusiasm, thoroughness and professionalism of Enric Ruiz-Gelices and Alexandra Stam, the Research Assistants at the Universities of Sussex and Dundee respectively. 


\section{Scope of report and recommendations from the steering group}

\section{Scope of report}

1. This report was commissioned following discussions among a wide group of stakeholders (see Annex $L$ ) with an interest in international student mobility. It was recognised that there was a lack of systematic information about the overall picture of UK student mobility, particularly individual mobility activity. Concern had been expressed about a decline in UK outward Erasmus mobility in comparison with other EU countries and the imbalance of incoming and outgoing Erasmus students to and from the UK. It became apparent during the discussions that while there was much anecdotal evidence of the underlying reasons for the imbalance, there were few available data and there were gaps in the collective knowledge. There was also considerable interest in learning more about student mobility outside Europe and outside the major schemes. The stakeholders agreed to sponsor a study which would examine the types and range of UK student international mobility, the reasons for student choice and how higher education institutions (HEls) manage mobility. An invitation to tender was issued and the Sussex Centre for Migration Research at the University of Sussex (SCMR) was selected to undertake the study. (SCMR subcontracted the Centre for Applied Population Research at the University of Dundee, and the report was prepared by the groups working together.) A steering group comprising representatives of the main stakeholders oversaw the progress of the study and advised the consultants.

2. The sponsors of the report are the UK higher education funding bodies, the Department for Education and Skills (DfES), UK Socrates Erasmus Council, HEURO, BUTEX and the British Council. The research and conclusions drawn are the authors' own and do not necessarily reflect the views of the sponsors.

3. The results presented here draw together a range of previously uncollated data, which are relevant to the overall picture of UK students' patterns of mobility, along with findings from specially commissioned surveys and new analysis of student data sources. Although these data can only give a partial picture of the multi-faceted context of student mobility, this report marks an important step in understanding how a variety of complex issues with a bearing on student mobility interact. The report makes it possible to answer at least some of the initial questions with which the stakeholders were concerned, and to pose others. Some of these are outlined below.

\section{Questions outside the scope of the study}

4. Many of the stakeholders believe that mobility is of benefit to students. Some of the results of the qualitative survey and comments from the survey of HEls support this belief, although this study did not explicitly focus on supplying hard evidence for this. The stakeholders recognise that assessment of the value of mobility schemes is at the moment based to some extent on a degree of judgement, by both providers and participants.

5. The wider context of the student experience, of which mobility is a part, is not fully considered in this report. For example, it does not explore the benefit to the UK student body of absorbing an increasing number of overseas students and whether this and other factors might offer students the benefit of international perspective.

6. It may be that what the trends in this report reveal is not attributable to any of the causes which might immediately suggest themselves, but rather that student aspirations in the global context are shifting. It may also be that providers of HE mobility opportunities need to reconsider the aims of such 
programmes and how these mesh with the wider social context. This report does not seek to offer conclusive statements on these issues.

\section{Language}

7. It has been asserted that a decline in numbers of students studying a language is responsible for declining numbers of mobile students. This study demonstrates a link between falling numbers of language students and a fall in outgoing UK Erasmus student numbers. The study shows that lack of language ability is a factor which students present as militating against mobility to a non-Anglophone country. It also shows an increase in students going to Anglophone countries, and to other destinations, even to other EU countries, but not as part of a nationally-managed scheme, such as Erasmus. In addition, there are some indications that students are becoming less interested in study abroad options, and that demand is increasing for work, or work and study placements. This last may indicate a link to the second most reported inhibitor to student mobility: concerns about the financial impact of a period spent abroad. It may be, therefore, that the decline in UK outward mobility to other countries in Europe is affected by a complex interplay of several factors, such as decline in language ability, limited opportunities for paid work placements, and the perceived high standards and marketability of US or other Anglophone education systems. If this is indeed the case, then, in seeking to encourage more students to be mobile, it may not be enough to increase the supply of study opportunities elsewhere in the EU. Rather, policy makers and all other stakeholders may wish to analyse carefully and respond creatively to student perspectives on mobility and the nature of student experience, for example by offering incentives for students from lower income groups, or forging partnerships, where appropriate, with countries to which UK minority ethnic groups may have historical and linguistic links, or developing more work or combined work and study opportunities. However, this is not to suggest that declining linguistic skills within the student body nationally should be ignored.

\section{The international context}

8. The UK is a signatory to the 'Bologna Process' towards a European Higher Education Area (EHEA) by 2010. This is intended to increase mobility between institutions in Europe and will have an impact on credit transfer arrangements through the European Credit Transfer System (ECTS). While Bologna is mentioned in the report, analysis of the likely long-term effects on the UK HE sector or student mobility were not part of the initial brief. National policy makers and HEls will need to monitor the evolving EHEA and assess its implications and impact on mobility. It is also important to note that many other complex historical, motivational and cultural factors, which are not examined in depth in this study, influence UK students' mobility.

\section{Improving the evidence base}

9. During this project, the Higher Education Statistics Agency (HESA) initiated a review of the requirements for data relating to student mobility and international provision. Through this review measures have already been identified and implemented to improve the quality of data relating to Erasmus exchanges captured through the HESA individualised student record. The review is ongoing, and the findings of this report will be considered to see if data relating to other schemes can and should be captured through the HESA data collection process. 


\section{Recommendations from the steering group}

10. As a result of the findings in this report the steering group makes several recommendations, which are presented below.

11. The steering group recommends that:

a. The Government take account of the findings in the report and, in particular, examine the implications for further development of language provision in schools. ${ }^{1}$

The Government take account of the need for a coordinated scheme in schools to promote and raise awareness of mobility opportunities at HE level (including full degree mobility).

The Government, HEFCE and employers' organisations commission further research on the benefits and outcomes of mobility, in particular, on whether international mobility can give UK graduates greater currency in the labour market, and, if so, how the UK benefits.

b. HEFCE include an examination of the cost implications of maintaining or increasing levels of international student mobility in its forthcoming review of funding for teaching.

c. HEls consider:

- the full range of mobility options on offer and how these match student demand/linguistic ability

- how information on mobility opportunities is disseminated, and its content, particularly in informing students how mobility is assessed. (The stakeholders note the QAA's Code of Practice in Placement Learning)

- monitoring mobility activity centrally, especially the collection of management information

- integrating planning for student mobility and exchanges into their international strategies, perhaps by developing a collective strategy which helps to underpin the efforts of mobility scheme organisers.

d. UK organisers of mobility schemes review provision in the light of changing patterns of mobility and the 'mobility culture', encouraging or influencing change where they are able, and consider, with HEIs, strategies for advertisement/dissemination and reaching out to schools.

e. National and international student organisations consider working with HEIs and other interested parties to advise on effective communication to students about international mobility opportunities, and to identify resources in support of this activity.

\footnotetext{
${ }^{1}$ The steering group notes the following statement from the DfES: 'The DfES has commissioned research into patterns of language learning and provision in higher education as part of its work on the national language learning strategy. That research will help in considering how best to increase the level of language learning - both formal and informal - and related student mobility, as well as the need to develop more inclusive institutional international policies in HEls.'
} 


\section{Executive summary}

1. This study was prompted by concerns about the low level of outward international student mobility (ISM) from the UK compared with other European countries. It was thought that low international mobility frustrates the development of a cosmopolitan and multilingual perspective among UK graduates. This could put the UK at a competitive disadvantage within the global economy. The defensive argument - that English has become the 'global language' - ignores the important intercultural learning experience that a period of study or work abroad can bring.

2. Eight questions frame the study:

- What is student mobility - how can it be defined?

- What trends can be identified in UK international student mobility and how do these compare with other countries?

- What are the main determining factors influencing students' mobility choices?

- To what extent is it useful to relate student mobility during the programme of study to prior mobility such as the gap year?

- What are perceived to be the main benefits of spending a period of time studying or working abroad?

- What are the main barriers to international mobility for UK students?

- How important is UK students' foreign-language knowledge in conditioning their propensity for international mobility?

- What are the main institutional factors driving, or constraining, student mobility?

3. In order to answer these questions a three-stage methodology was employed, each involving a different scale of analysis:

- a review and synthesis of available statistics on UK, EU and global student mobility, in order to put the UK situation in context

- a questionnaire survey of all publicly-funded higher education institutions (HEls) in the UK, in order to document and quantify those types of student mobility for which statistics are not available, and to bring out the 'institutional perspective'

- site visits to 10 HEls to collect first-hand information on the 'student perspective' via questionnaires, interviews and focus groups.

4. The 'evidence base' for the study consists of a statistical and literature review, completed institutional questionnaires from $80 \mathrm{HEls}$, face-to-face interviews with 46 academics and 'mobility managers', 1,200 questionnaires from carefully stratified samples of students, and interviews and discussions with 180 students.

5. We define ISM as any form of international mobility that takes place within a student's programme of study in higher education (HE). The length of absence ranges from a short trip to a full-duration programme of study such as a degree. In addition to study at a foreign $\mathrm{HEI}$, mobility can also involve a period in a workplace or other non-HE environments.

6. Globally 1.8 million students were studying outside their country of origin in 2000 . This figure is projected to rise to 7.2 million by 2025 . Although the UK has higher rates of outward mobility than other English-speaking countries such as the United States and Australia, it has lower rates than most other EU countries. Foreign students in the UK greatly outnumber UK students studying abroad. 
7. Erasmus data on European exchanges show that numbers of incoming students to the UK are twice the outward flow, and numbers of outgoing students have fallen by nearly a third since the mid-1990s.

8. The decline in UK Erasmus student flows to Europe should be set against growth of other types of student mobility and flows to other destinations, particularly North America and Australia.

9. At the institutional level, statistical analysis shows Erasmus outward trends correlate strongly with two key variables: research activity of HEls, and changing numbers of students doing language degrees.

10. Mobility is increasingly, and disproportionately, concentrated in pre-1992 universities. This category of $\mathrm{HEl}$ accounted for half of all outward mobility in 1995-96, two-thirds in 2002-03. Corresponding shares for post-1992 universities were 40 per cent in 1995-96 and one quarter in 2002-03. The small remaining fraction is accounted for by the non-university HEl sector.

11. Only one third of the HEls which responded appeared to have a specific plan for student mobility. Promoting outward mobility is secondary to increasing the recruitment of fee-paying overseas students.

12. HEls and their departments are keen to minimise Erasmus imbalances between large incoming numbers and small outgoing flows, since there is a financial burden involved. Partly as a result, mobility is being redirected from Europe to North America, Australia and other destinations. Work placements are becoming more popular among students, but they can be costly to administer.

13. The institutional surveys confirmed the key role of language in both channelling mobility and acting as a barrier. However, most staff thought that financial problems were an even bigger obstacle to maintaining or increasing outward mobility.

14. Both the student questionnaire survey and the student interviews confirmed the staff views about finance and language being the two main barriers to mobility. Other factors which had some importance in the eyes of students were lack of information (or having information too late), actual or perceived academic/institutional barriers (course structures, credit transfer, worries over grades, for example), and attitudinal factors (fear of the unknown, and so on).

15. Mobile students are essentially of two types: those who go abroad as a compulsory part of their studies (mainly language students), and those who choose mobility for a range of personal, educational and professional reasons. Statistical analysis of matched Erasmus-HESA datasets on individual students show that outgoing Erasmus students from the UK are more likely to be younger, female, white and from families in the higher social classes, when compared with nonmobile students.

16. Students who had lived or travelled abroad prior to HE (referred to as prior mobility in this report), for example during a gap year, were more likely to engage in formal mobility during their time in $\mathrm{HE}$.

17. Mobile students generally felt very positively about their foreign experience: 95 per cent thought it had enhanced their personal development, and 90 per cent felt that it was relevant to the development of an international career. Strict academic benefits were stressed less often. 
18. Of those who had been abroad, relatively few encountered major problems. Even finance, the most often-cited problem, was mentioned by only 22 per cent of mobile students; absence from a girl- or boy-friend was cited by 20 per cent.

19. Nearly half the non-mobile final-year students questioned regretted not going abroad. Among firstyears, most interest was expressed in work placements or mixed work/study arrangements, rather than pure study abroad.

20. The following policy implications arise from the study:

- A need for more complete and regularly collected data on student mobility.

- Financial and linguistic constraints inhibit 'traditional' HE mobility such as the 'European Year Abroad' undertaken by language students as a part of their study; there is an under-provision of work and mixed study/work schemes, and these are needed to respond to current student demand.

- HEls could be more proactive in promoting student mobility, balancing it against the priority to recruit high-fee overseas students.

- Information and publicity about HE mobility schemes could be expanded, and targeted at schools and further education colleges.

- Consideration needs to be given to language learning at all levels in the UK education system.

- Consideration needs to be given to how access to mobility can be broadened; at present many students are 'socially excluded' from mobility opportunities because of their financial situation, family and class background, and linguistic limitations. 


\section{Context, aims and organisation of the study}

\subsection{Context of the study}

This study analyses outward higher education student mobility from the United Kingdom. International student mobility (ISM) involves students leaving their country of residence for a period of higher education abroad, or to pursue a related activity such as a foreign work placement or study tour.

One major reason for undertaking this study was the concern expressed by some stakeholders about the low level of outward mobility by UK-based students compared with other EU countries. This lack of mobility is highlighted by a decline in numbers of UK students going on Socrates-Erasmus exchanges from 11,988 students in 1994-95 to 7,956 in 2002-03. If current rates of decline continue, by 2006 there will be only about 6,500 UK students taking up Erasmus opportunities.

Low student mobility links to wider concerns about the lack of a cosmopolitan and multilingual perspective among UK graduates in an increasingly globalised labour market. It might put the UK economy at a competitive disadvantage, especially in fields such as business, research and international organisations. There is an argument that English has become the 'global language' and that UK students should not feel the need to learn another language, but this ignores the important intercultural learning experience that a spell abroad can bring.

Uptake of Erasmus places is one indication of mobility of UK students, but consistent and comparable data on non-Erasmus mobility are scarce. Another reason for this study was therefore to document other types of international mobility in the higher education sector.

This study also explores the wider context in which student mobility occurs. In advanced societies, international mobility is much more widespread and frequent than it was in the past. Although older age groups are not excluded from this 'mobility culture', it is young people, especially those with good educational backgrounds, who travel abroad the most. Many are likely to have been abroad with their parents, on school trips, or as part of 'gap year' experiences between school and university.

There are many other influences on student mobility. In Europe it is affected by key political changes in the European Union. One example is the Bologna process. This initiative aims to harmonise higher education systems across the EU, with mutual recognition of credits and qualifications. Another example is the enlargement of the EU in 2004. Many students in the 10 new countries want to study in an English-language environment (HEPI 2004) and will be entitled to do so within the current SocratesErasmus scheme. Whether UK students will reciprocate by moving in equal numbers to these new destinations remains to be seen, but indications are that they are unlikely to do so under current schemes.

The UK's position in the world is very complex, given its high degree of involvement in Europe, North America, and the developing world. This wide global reach means that viewing its student mobility largely within a European context may be misplaced: ties of language, culture and history mean that the United States, Canada, Australia and Singapore are also likely destinations. Hence, in this study, both European and non-European mobility are considered.

This report considers how students perceive the benefits of, and barriers to, mobility and what factors are critical in shaping their mobility choices. We also ask whether the current pattern of international mobility matches UK students' aspirations. Finally we consider the policy implications of the changing dynamics of UK student mobility. 


\subsection{Eight key questions}

The study addresses eight questions, as shown below.

\section{Eight key questions}

1. What is student mobility - how can it be defined?

2. What trends can be identified in UK international student mobility and how do these compare with other countries?

3. What are the main determining factors influencing students' mobility choices?

4. To what extent is it useful to relate student mobility during the programme of study to prior mobility such as the gap year?

5. What are perceived to be the main benefits of spending a period of time studying or working abroad?

6. What are the main barriers to international mobility for UK students?

7. How important is UK students' foreign-language knowledge in conditioning their propensity for international mobility?

8. What are the main institutional factors driving, or constraining, student mobility?

Each question can be broken down further. For instance, under question 3 a range of factors - personal characteristics, financial situation, career ambitions, type of course and university - could be relevant, and relate to each other in complex ways. To take another example, the gap year (question 4) could be hypothesised as either a motivating factor for mobility during the study programme, or a substitute for in-programme mobility.

These eight questions are discussed in this report. Conclusions are given in Chapter 5.

\subsection{Organisation of the research}

The research lasted for one year, structured into three separate, though linked studies.

Study 1 reviewed the literature on student mobility and collated available statistical data. A review of the limited literature on ISM is at Annex A. Examination of existing statistical data helped set the UK'S trends against those of other countries.

Study 2 surveyed all publicly funded UK higher education institutions. Its aim was to document and quantify types of student mobility by sending a questionnaire to all HEIs in the UK.

Study 3 was the largest of the three and involved the main 'field' surveys. We collected primary data on the experiences and views of mobility from over 1,400 students and staff in 10 selected HEls.

Questionnaires and interview techniques were employed.

The 'results' chapters of the report are sequenced in telescoping scale:

- Chapter 2 synthesises ISM trends for the UK and comparative countries, based on published data and on returns from the HEI questionnaire.

- Chapter 3 covers the institutional perspective. It collates the views of academics and 'mobility managers' on the organisation and promotion of mobility, and on key 'drivers' and 'barriers'. 
- Chapter 4 explores the student perspective. It combines quantitative and qualitative analysis of, respectively, student questionnaire and interview surveys.

Throughout, key methods and findings in the text are supported by supplementary information in the annexes. Annex B provides further information about the methods used as well as copies of the main research instruments.

\subsection{Definition of international student mobility}

We define ISM as any form of international mobility which takes place within a student's programme of study in higher education. The length of absence can range from a short trip to the full duration of a course of study. In addition to study in a foreign HEI, mobility can include a period in a workplace or other non-HE environment. In order not to study HE mobility in isolation, we also consider the relevance of prior mobility, such as the gap year.

One useful threefold typology of ISM is used by the UK Higher Education Statistics Agency (HESA):

- mobility for an entire programme of study (diploma mobility)

- for part of a programme (credit mobility)

- other voluntary moves undertaken for a range of personal reasons.

Such mobility can be inward or outward, and can be either reciprocal (student exchanges) or one-way. 


\section{The national and international statistical picture}

Global data on students studying outside their country of origin are published by UNESCO and OECD. Erasmus and Leonardo annual datasets refer to the $\mathrm{EU}$, while the British Council issues annual data on language assistants and participation in the International Association for the Exchange of Students for Technical Experience (IAESTE).

Most such sources yield only basic data, such as numbers of students by destination country. Depending on the data source, some light may be shed on other variables, such as type of activity (academic study, work placement and so on), length of time spent abroad (such as one term, one year), timing of the mobility (undergraduate, postgraduate, vacation), and the role, if any, of foreign language learning.

\subsection{International trends and comparisons: where the UK fits in}

Globally, student mobility has grown considerably over the past 25 years. This reflects the general drive taking place within the global knowledge economy. It also indicates the specific recognition by some countries of the value of international awareness among students who are the professional and managerial classes of the future (Davis et al. 1999).

The UK is a key node in this global circulation of students, especially as a destination. Over the last two decades there have been dramatic increases from EU countries (especially Greece), and significant growth from the US, China, Japan and some of the wealthier Commonwealth countries.

Cross-sectional data from OECD (2001) enable us to see how the UK compares with other countries in terms of students studying abroad. Comparative statistics of this kind have to be interpreted with care because definitions of 'student' and 'mobility' vary greatly from one country to another (see Annex C Table C1 for definitions of foreign students in OECD countries).

Table 1 below shows that in 2000 the UK sent 13.5 students to other OECD countries for every 1,000 students enrolled in its tertiary education system. The US and Australia were by far the most popular destinations. Less than half of UK mobile students went to the EU. The UK's outflow rate was higher than the United States or Australia, but lower than other major EU states like France or Germany. The data include both students taking a full degree programme abroad and those studying for shorter periods such as a year or a semester (though there may be some undercounting of the latter).

Table 1 suggests that large countries have lower mobility. Cultural or geographical remoteness also puts a brake on mobility. High levels of mobility result from the spatial and institutional proximity of EU countries.

OECD data also provide an opportunity to compare student mobility by the language of the destination country: 43 per cent of UK students went to countries with a different language. This was much less 'conservative' than students from New Zealand, Canada and Australia. But the British were more linguistically conservative in their choice of destination than all their European neighbours except Ireland and Austria (see Annex C Table C5). 
Table 1: A comparison of outward student mobility from UK, France, Germany, Australia and US to principal destinations, 2000 (number of mobile students enrolled in tertiary education in other countries per 1,000 students enrolled in country of origin)

\begin{tabular}{lrrrrr}
\hline & Origin UK & Origin France & Origin Germany & Origin Australia & Origin US \\
\hline Destination & & & & & \\
Australia & 2.2 & 0.1 & 0.5 & $\mathrm{Na}$ & 0.2 \\
Austria & 0.1 & 0.2 & 2.9 & $\mathrm{Na}$ \\
Belgium & 0.1 & 4.9 & 0.3 & $\mathrm{Na}$ & $\mathrm{Na}$ \\
Canada & 0.6 & 2.2 & 0.4 & 0.5 & 0.3 \\
France & 1.6 & - & 2.6 & 0.2 & 0.2 \\
Germany & 1.3 & 3.2 & - & 0.3 & 0.3 \\
Ireland & 0.9 & 0.3 & 0.2 & 0.1 & 0.1 \\
Japan & 0.2 & 0.1 & 0.1 & 0.4 & 0.1 \\
Netherlands & 0.3 & 0.1 & 1.1 & $\mathrm{Na}$ & $\mathrm{Na}$ \\
Spain & 1.3 & 2.3 & 1.9 & 0.1 & 0.1 \\
Sweden & 0.4 & 0.5 & 0.9 & 0.2 & 0.1 \\
Switzerland & 0.1 & 1.4 & 2.7 & $\mathrm{Na}$ & $\mathrm{Na}$ \\
UK & - & 6.2 & 6.6 & 1.5 & 0.8 \\
United States & 3.8 & 3.2 & 4.4 & 2.9 & - \\
& & & & & $\mathbf{6 . 3}$ \\
\hline Total & $\mathbf{1 3 . 5}$ & $\mathbf{2 5 . 5}$ & $\mathbf{2 6 . 0}$ & $\mathbf{2 . 5}$ \\
\hline
\end{tabular}

Source: Adapted from OECD (2001).

$\mathrm{Na}=$ not applicable

To summarise, it would appear that the UK, while being an exceptionally attractive student destination, does not have a particularly low level of outward mobility when global comparisons are made. The rate is, however, lower than other EU states, which may be a cause for concern. Our view is that the level of UK outward flows fits the trends discussed above: that the scale of flows is influenced by size of country of origin, its geographical remoteness, its institutional proximity to a specific student exchange system and the strength or otherwise of language barriers.

\subsection{Erasmus mobility}

Socrates-Erasmus is the best known organised student mobility programme in Europe, accounting for around one-third of all mobile students in Europe. During the 1990s the Erasmus scheme became increasingly popular across the EU, with total student mobility rising in every year except 1995-96 (Mitchell 2001).

It is worth analysing the available datasets on European movements to explore trends and possible factors of mobility at a variety of levels - national, institutional, and individual. Annex D provides a statistical analysis of individual student data matched between Erasmus and HESA records.

Taking overall student numbers during recent years, Germany, the UK, France, Italy and Spain together send and receive most students (send 71 per cent, receive 74 per cent). The UK has been the largest host nation within the Erasmus scheme. More significantly, it has been the country with the largest imbalance of incoming and outgoing students (see Figure 1). Countries which have a significant element of their HE system taught in English are the main net recipients of students. Countries which have instruction in other languages are the main net senders of students. 
Figure 1: Net balance of Erasmus students across the EU, 2001-02

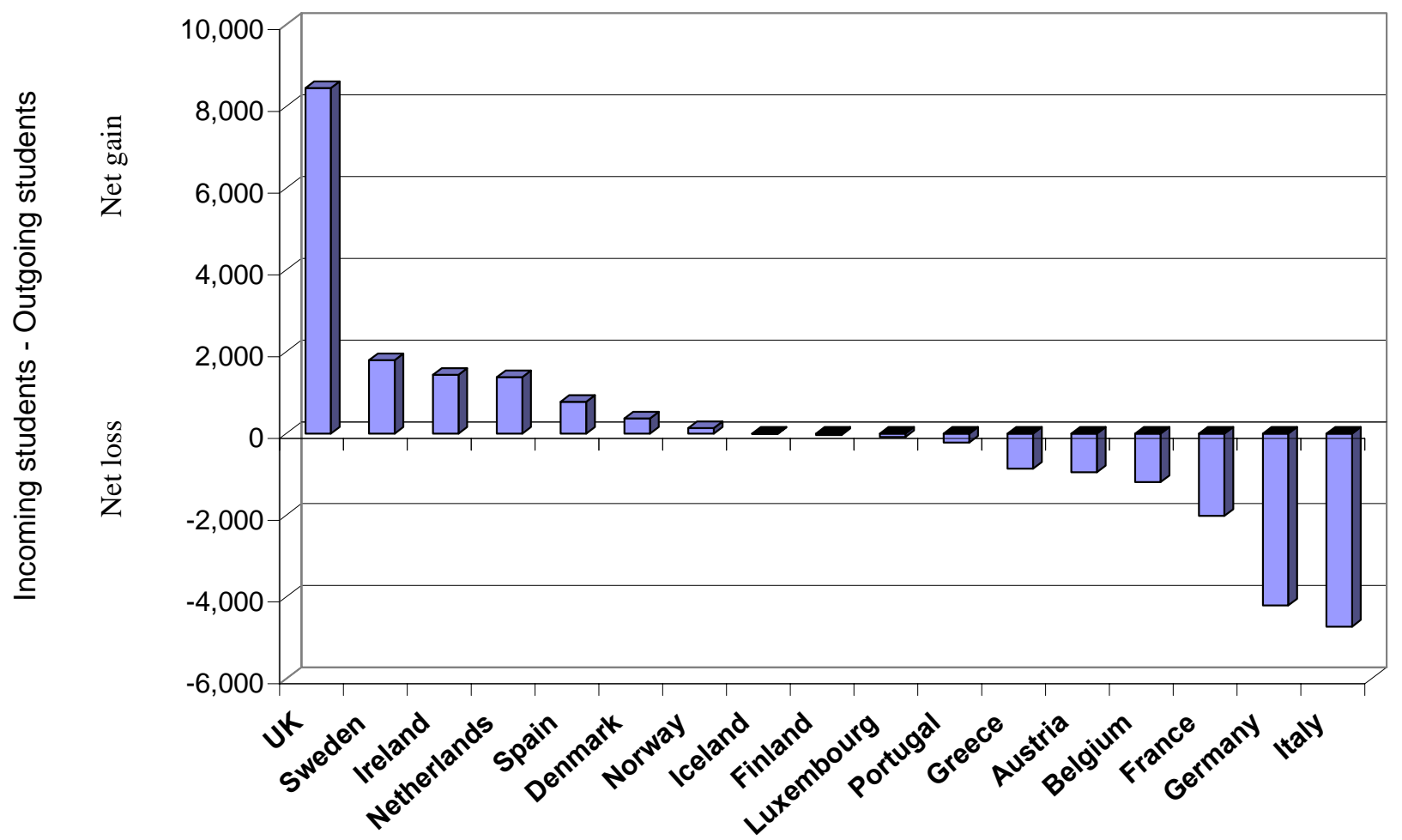

Source: Erasmus student mobility 2001. SCHE/03/07 - Annex

The decline in the UK student outflow is marked (see Figure 2). In 2002-03 the number fell to only 7,956 compared with 11,988 in 1994-95. Inward mobility has been close to twice the out-movements since the mid-1990s. Figure 3 shows the decline in UK out-mobility in relation to specific destinations.

The UK trend is contrary to that in all other EU countries except Sweden and the Netherlands; in these countries there has also been some fall-off, but less dramatic and more recent than for the UK.

The UK figures raise two questions:

- What kinds of student participate in this type of organised mobility?

- Why is the scheme operating at two-thirds of the level of mobility achieved a decade ago?

Statistical analysis of the characteristics of UK students participating in the Erasmus scheme in 2002-03 shows that they are younger, more likely to be female, white and from families in the higher social classes, when compared with other students (see Annex D). Table 2 highlights just how selective mobility is in terms of two of these criteria (ethnicity and class). To some extent these selective characteristics reflect the fact that language students (who make up a high proportion of UK Erasmus students) are disproportionately drawn from certain segments (female, white, high social class) of the population, but the selectivity is most obvious for non-language students. When Erasmus students on courses without a language element are compared with the student population as a whole, there is a marked bias in favour of white ethnic groups and students from higher social classes. It would appear, therefore, that student mobility choices are affected by deep social parameters. Alternatively, as Annex D suggests, it may be that unidentified common characteristics of courses with no language component account for the effect.

Also important for explaining the trends in Figures 2 and 3 is the fact that the number of language students in the UK has been in sharp decline. As Annex D shows, UK Erasmus outgoing students in 2002-03 were only 68 per cent of those in 1995-96, while the number of students recorded by HESA as 
studying languages dropped to 72 per cent of the 1995-96 level. This leads to a wider debate about why language learning in the UK is in decline, which lies beyond the remit of this report.

Figure 2: UK - incoming and outgoing students (1987-88 to 2002-03) on Socrates-Erasmus programmes

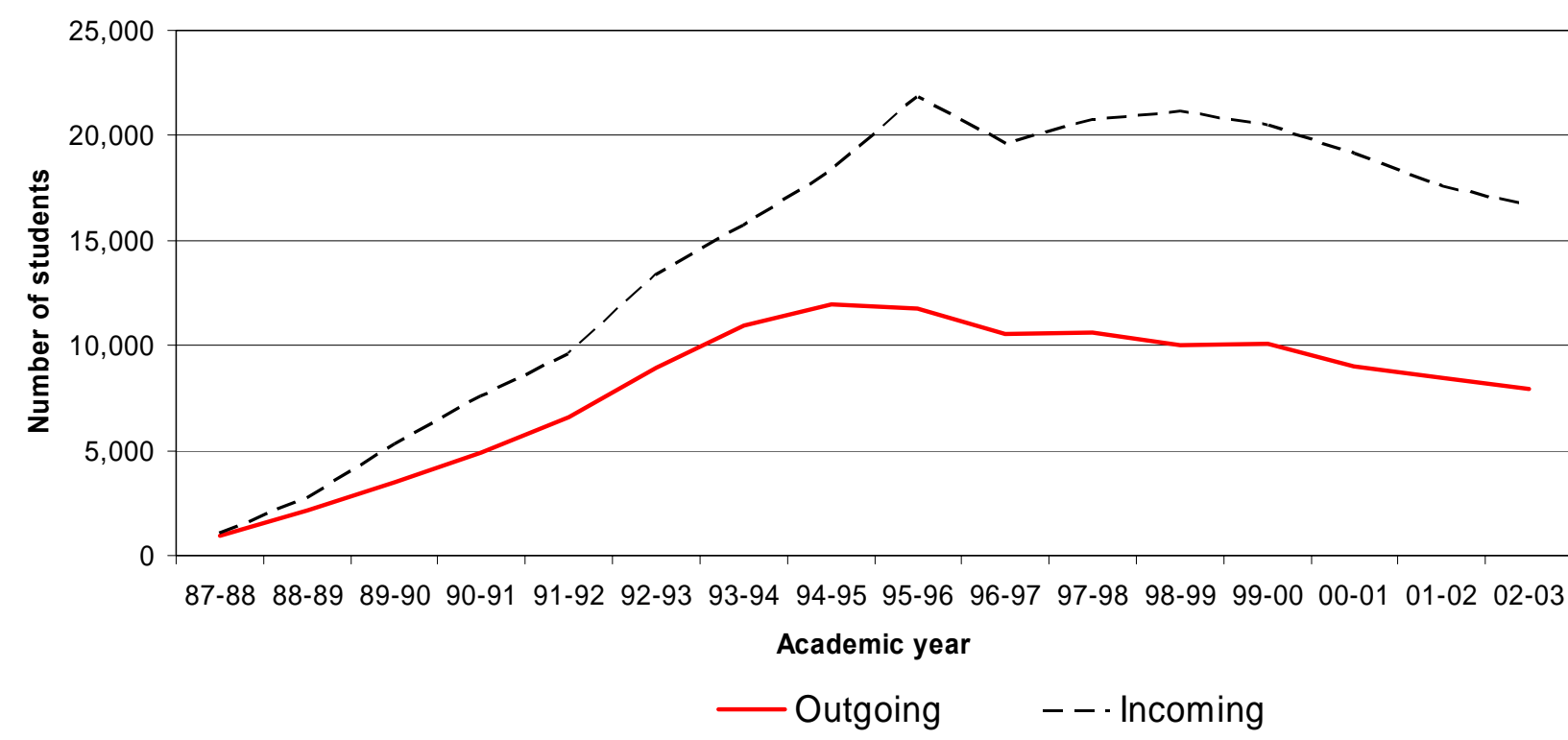

Source of data: UK Socrates-Erasmus Council

Figure 3: UK Erasmus outward mobility: main destinations (1987-88 to 2001-02)

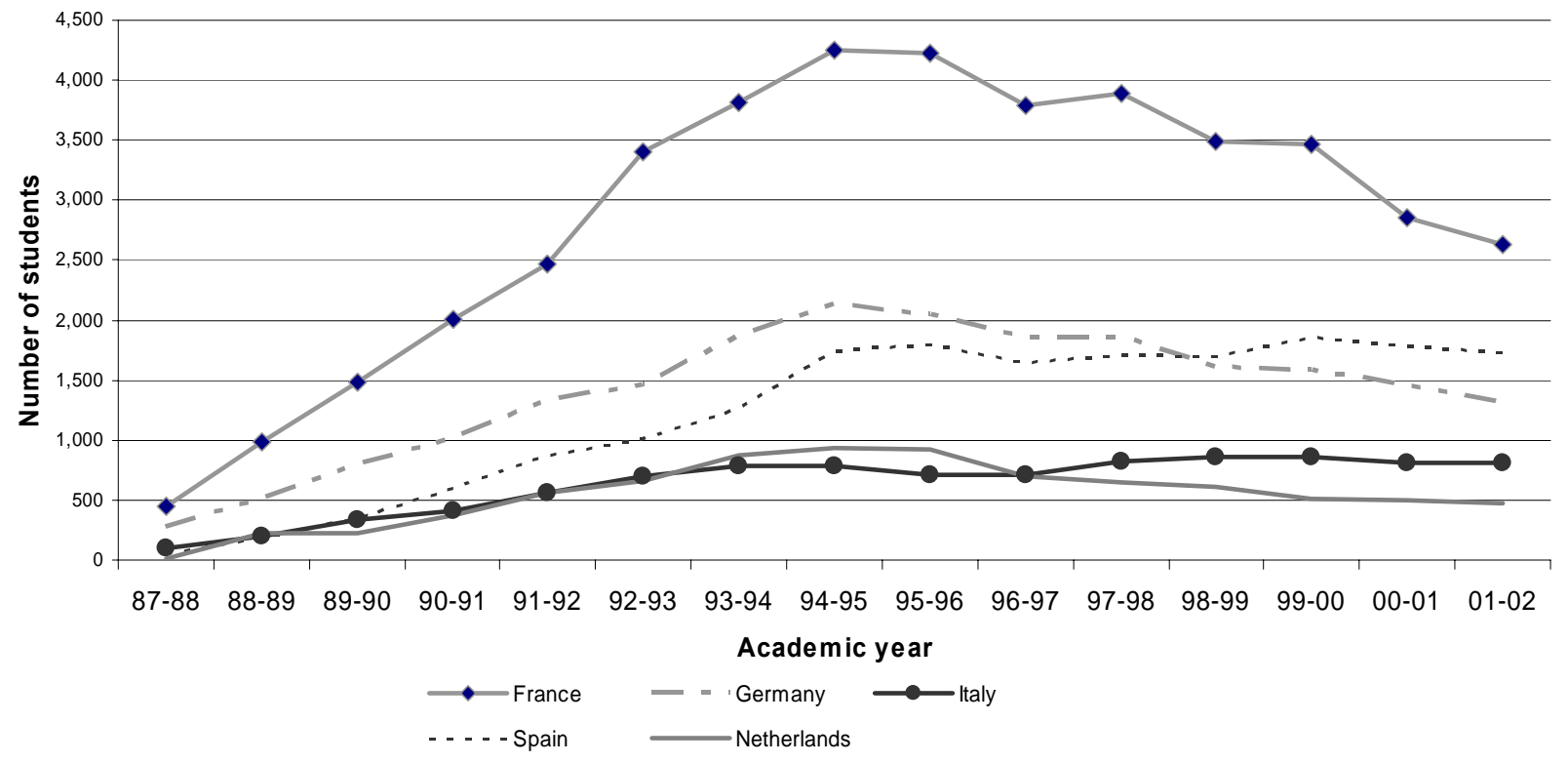

Source of data: UK Socrates-Erasmus Council

There is also institutional differentiation in Erasmus participation. In 2002-03 149 UK HEls participated in Erasmus. Of these only 27 institutions sent more than 100 students; 53 sent less than 20. In 1994, by comparison, not only did more institutions participate (159), but on average each one sent many more students. Thus the decline in outwardly mobile students reflects both a fall-off in institutional involvement in Erasmus exchanges and a reduction of participation in those institutions continuing with the scheme. However, this trend is not true of all institutions: $45 \mathrm{HEls}$ increased their participation between 1994-95 and 2002-03, and 13 doubled the size of their outflows. These findings point to the importance of the institutional dimension of Erasmus linkages, including the subject mix and commitment to student mobility. 


\begin{tabular}{lrr} 
& Erasmus & Non-Erasmus \\
\hline Social class & & 76 \\
Total students of high social class \% & 83 & 83 \\
Studying a language, \% high social class & 84 & 76 \\
Not studying a language, \% high social class & 82 & 16 \\
\hline Ethnicity & 8 & 9 \\
Total students non-white \% & 8 & 16 \\
Studying a language, \% non-white & 9 & \\
Not studying a language, \% non-white & & \\
\hline
\end{tabular}

Source: Annex D, Tables D7 \& D8

Statistical analysis at the HEl level offers further explanation for the fall-off (see Table 3). The proportion of students taking up Erasmus places is strongly associated with institutional involvement in language teaching. Business studies shows a similar, but less strong, positive relationship with outward mobility. Research activity also correlates strongly with outgoing flows of students. Given that performance in the Research Assessment Exercise (RAE) was judged in terms of international excellence, it is not surprising that the international reach of an institution as indicated by student mobility is associated in this way, although the link with international excellence in research may not be a direct one.

Table 3: Correlation of explanatory variables with the institutional mobility rates for the 2002-03 Erasmus outgoing student flow

\begin{tabular}{ll}
\hline Explanatory variable & Statistical significance \\
\hline \% Full-time first degrees in languages (2000-01) & Very significant \\
\% Full-time first degrees in law (2000-01) & Not significant \\
\% Full-time first degrees in social science (2000-01) & Not significant \\
\% Full-time first degrees in business studies (2000-01) & Very significant \\
$\%$ Staff entered as research active in the 2001 RAE & Very significant \\
$\%$ Staff in RAE rated 5 or 5* departments (2001) & Very significant \\
\hline
\end{tabular}

See Annex C, Table C12, for details of the tests on which this table is based.

A more detailed statistical examination of change in Erasmus mobility rates was undertaken. This was restricted to those HEls with higher levels of participation (sending 30 or more students) in the scheme in 1994-95. This confirmed that between 1994-95 and 2002-03 there were just two main determinants of changing mobility rates. The proportion of staff who worked in 5 or $5^{\star}$ rated departments was by far the strongest correlate; also significant was the changing proportion of students taking language degrees. These two variables accounted for over 40 per cent of the variance between institutions in the change in Erasmus participation (see Annex C, Table C13).

\subsection{Other national and internationally managed mobility schemes}

There are many other UK student mobility programmes. Although smaller than Erasmus, they provide important channels for different kinds of exchanges. Other Socrates programmes include the Lingua network, which supports projects that raise awareness of language learning opportunities, and the Grundtvig scheme in adult education and lifelong learning. We do not discuss these schemes here, because they are not primarily focused on students in the HE sector. 
The rest of this section discusses three British Council-administered schemes, chosen to illustrate the variety of non-Erasmus mobility arrangements. Table 4 shows the number of students participating in these schemes over an eight-year period.

Table 4: UK students going abroad under three British Council-managed mobility schemes

\begin{tabular}{rrrr}
\hline Year & IAESTE & Language assistants & Leonardo \\
\hline 1995 & 160 & 2,624 & N/A \\
1996 & 173 & 2,585 & N/A \\
1997 & 220 & 2,165 & N/A \\
1998 & 200 & 2,373 & N/A \\
1999 & 203 & 2,193 & N/A \\
2000 & 204 & 1,942 & 137 \\
2001 & 196 & 1,801 & 833 \\
2002 & 171 & 1,869 & 641 \\
\hline
\end{tabular}

$\mathrm{N} / \mathrm{A}=$ not applicable

Source: British Council database

Most IAESTE students are drawn from science and engineering, and participate in the scheme during vacations. The scheme long predates Erasmus; it was formed in 1948 and now involves over 80 countries worldwide. In 2000 the IAESTE network facilitated some 5,515 multilateral exchanges worldwide, including 204 students from the UK going to other countries. Many go from Northern Ireland. In recent years the range of destinations has increased, although the number of students participating has declined. However, student demand remains buoyant. Limitations on the supply/capacity side include the willingness of employers to offer appropriate work placements, the UK's capacity to reciprocate, and staff administrative resources.

The Language Assistant scheme sends about 2,000 assistants abroad every year. Most spend a year abroad, typically the third of a four-year degree programme. This form of mobility has declined somewhat during the last decade. Students studying Portuguese and Russian have virtually disappeared from the scheme, and there is a decline in students going to France and Germany. Students going to China in 2002-03 contributed to a partial revival of total numbers. The main reason for the overall decline in UK students in the scheme has been the downward trend in the number of UK undergraduates taking modern language degrees and hence seeking work experience overseas.

The European Community's Leonardo scheme aims to use transnational cooperation and skill mobility to enhance vocational training. UK undergraduates engage in managed work placements of three months or more in Europe. As with many other schemes there is a major imbalance in flows, with UK receiving as many trainees from other countries as all other receiving countries taken together.

This review of scheme-led mobility, brief and partial, has highlighted some common features:

- there are several mobility channels open to UK students in addition to Socrates-Erasmus

- some of these schemes show similar trends to Erasmus, being affected by the downturn in the number of UK students studying languages in the UK and often having an imbalance of inward over outward flows

- some work placement and vocational training schemes have recorded no decline in demand from students; their potential for contributing to the UK economy merits wider consideration.

- many schemes exist that are specific to certain parts of the country or to individual HEls and for which no national statistics exist. This makes it difficult to quantify total student mobility outside the Socrates-Erasmus channel. 


\subsection{Student mobility outside the Socrates-Erasmus programme}

To collect cross-sectional data about outgoing student mobility under schemes and initiatives that lie outside Erasmus, IAESTE and Language Assistants, a questionnaire was sent to all UK HEIs asking about trends since 1995-96 (see Annex B2). The results showed rising mobility in terms of crude numbers of outgoing students; the rate of increase was considerably faster than that of total numbers of students enrolled in HEls over the same period.

We ran checks to ensure that there was no bias in the survey - for instance that institutions with higher mobility rates were more likely to reply (see the discussion in Annex B2).

Table 5 records outgoing mobility for the 80 respondent HEls by main destination area for 2000-01 to 2002-03. The trends are quite varied. In absolute terms the United States is by far the most important destination for UK non-Erasmus mobility, accounting for 41 per cent of the total students moving in 2002-03. With Canada included, North America receives just over half of UK students. Australia and New Zealand account for another 8 per cent. Taken together, these four countries comprise 60 per cent of that part of total UK student mobility measured by Table 5 .

Table 5: Non-Erasmus outward mobility from 80 UK HEls by main destination, 2000-01 to 200203

\begin{tabular}{|c|c|c|c|c|c|}
\hline $\begin{array}{l}\text { Main countries of destination } \\
(>50 \text { in } 2002-03)\end{array}$ & $2000-01$ & 2001-02 & 2002-03 & $\begin{array}{r}\% \text { change } \\
2000-01 \text { to } \\
2002-03\end{array}$ & $\begin{array}{r}\% \text { of total } \\
\text { mobility } \\
2002-03\end{array}$ \\
\hline \multicolumn{6}{|l|}{ Top ten countries } \\
\hline US & 1,283 & 1,509 & 1,554 & 21.1 & 41.1 \\
\hline Canada & 292 & 408 & 406 & 39.0 & 10.7 \\
\hline Australia & 139 & 223 & 235 & 69.1 & 6.2 \\
\hline New Zealand & 57 & 66 & 75 & 31.6 & 2.0 \\
\hline Japan & 68 & 81 & 114 & 67.6 & 3.0 \\
\hline Singapore & 60 & 64 & 77 & 28.3 & 2.0 \\
\hline Hong Kong & 50 & 56 & 54 & 8.0 & 1.4 \\
\hline France & 169 & 229 & 275 & 62.7 & 7.3 \\
\hline Germany & 77 & 137 & 102 & 32.5 & 2.7 \\
\hline Spain & 42 & 77 & 82 & 95.2 & 2.2 \\
\hline \multicolumn{6}{|l|}{ Regions } \\
\hline North America & 1,575 & 1,917 & 1,960 & 24.4 & 51.8 \\
\hline Australia, New Zealand & 198 & 291 & 314 & 58.6 & 8.3 \\
\hline Asia & 226 & 324 & 391 & 73.0 & 10.3 \\
\hline EU & 471 & 655 & 689 & 46.3 & 18.2 \\
\hline Other European & 80 & 80 & 88 & 10.0 & 2.3 \\
\hline Latin America \& Caribbean & 88 & 131 & 125 & 42.0 & 3.3 \\
\hline Other and unspecified & 158 & 218 & 217 & 37.3 & 5.7 \\
\hline Total students & 2,796 & 3,614 & 3,784 & 35.3 & 100.0 \\
\hline
\end{tabular}

Source: Authors' survey

These four countries have one thing in common; they are Anglophone. Indeed, if we make an assumption about some of the mobility in the 'Other and unspecified' category (which includes South Africa and the University of the West Indies), the total mobility to English-speaking countries rises 
above 65 per cent - maybe as high as 70 per cent if we assume Hong Kong and Singapore are at least partly Anglophone.

While North America has enjoyed an upward trend as a destination, its share of the total has dropped from 56.3 to 51.8 per cent. This might be accounted for by the growing popularity of Australasia and Asia as destinations. It is also interesting that the EU commands 18 per cent of the market and this is outside the Socrates-Erasmus and Language Assistant movements.

Another notable feature from the HEI questionnaire survey is how institutional schemes offering work placements abroad emerge as significant. A third of all student mobility involved work placements of some kind.

To compare Table 5 with Erasmus mobility, Table 6 sets out the Erasmus outflows for the same 80 UK HEls and the same period. Just the principal destinations are given. Comparing the totals for the three years, the Erasmus trend is opposite to the non-Erasmus trend: the latter more than compensates for the decline in the former; for the 80 respondent HEls: Erasmus mobility declined by 647 and nonErasmus mobility grew by 988 .

Table 6: Erasmus outward mobility from 80 UK HEls by main destination, 2000-01 to 2002-03

\begin{tabular}{|c|c|c|c|c|c|}
\hline & 2000-01 & 2001-02 & $2002-03$ & $\begin{array}{r}\% \text { change } \\
2000-01 \text { to } \\
2002-03\end{array}$ & $\begin{array}{r}\% \text { of total } \\
\text { mobility } \\
2002-03\end{array}$ \\
\hline Austria & 87 & 68 & 14 & -83.9 & 0.4 \\
\hline Belgium & 78 & 96 & 54 & -30.8 & 1.4 \\
\hline Denmark & 72 & 81 & 70 & -2.8 & 1.9 \\
\hline Finland & 143 & 130 & 143 & 0 & 3.8 \\
\hline France & 1,395 & 1,287 & 1,184 & -15.1 & 32.0 \\
\hline Germany & 706 & 619 & 556 & -21.2 & 15.0 \\
\hline Italy & 379 & 363 & 306 & -19.3 & 8.2 \\
\hline Netherlands & 253 & 251 & 207 & -18.2 & 5.5 \\
\hline Portugal & 52 & 54 & 41 & -21.2 & 1.1 \\
\hline Spain & 865 & 816 & 822 & -5.0 & 22.0 \\
\hline Sweden & 174 & 154 & 150 & -13.8 & 4.0 \\
\hline Other countries & 179 & 184 & 189 & 5.6 & 5.1 \\
\hline Total students & 4,383 & 4103 & 3,736 & -14.7 & 100.0 \\
\hline
\end{tabular}

Source: UK Socrates-Erasmus Council

The survey also showed mobility differences by institutional type (see Table 7). Again, non-Erasmus and Erasmus flows can be compared. The Erasmus trends, although downwards overall, are virtually identical to the non-Erasmus as regards their distribution by HEI type. The pre-1992 universities account for the major share of outward mobility. Moreover, their share has progressively increased from half of the total in 1995-96 to two-thirds in 2002-03. The post-1992 universities' share has steadily decreased, falling from nearly 40 per cent in 1995-96 to one quarter in 2002-03. The remainder of the HE sector accounts for a smaller fraction - less than one tenth.

Table 7: Non-Erasmus and Erasmus outward mobility by type of HEI, 2000-01 to 2002-03

Type of HEl 2000-01 2001-02 2002-03

$\begin{array}{rrrrr}\text { No. } & \% & \begin{array}{r}\text { No. } \\ \text { students }\end{array} & \% & \begin{array}{r}\text { No. } \\ \text { students }\end{array}\end{array}$




\begin{tabular}{lrrrrrr} 
Non-Erasmus & & & & & & \\
Pre-1992 universities $(\mathrm{n}=31)$ & 1,739 & 62.2 & 2,361 & 65.3 & 2,474 & 65.4 \\
Post-1992 universities $(\mathrm{n}=21)$ & 838 & 30.0 & 934 & 25.8 & 962 & 25.4 \\
Other HEls* $(\mathrm{n}=28)$ & 219 & 7.7 & 321 & 8.9 & 348 & 9.2 \\
Total & 2,796 & 100.0 & 3,616 & 100.0 & 3784 & 100.0 \\
\hline & & & & & & \\
Erasmus & & & & & & \\
Pre-1992 universities $(\mathrm{n}=31)$ & 2,734 & 62.4 & 2,702 & 65.9 & 2,550 & 68.2 \\
Post-1992 universities $(\mathrm{n}=21)$ & 1,291 & 29.4 & 1,114 & 27.1 & 972 & 26.0 \\
Other HEls* $(\mathrm{n}=28)$ & 358 & 8.2 & 287 & 7.0 & 216 & 5.8 \\
Total & 4,383 & 100.0 & 4,103 & 100.0 & 3,738 & 100.0 \\
\hline Total & $\mathbf{7 , 1 7 9}$ & $\mathbf{1 0 0 . 0}$ & $\mathbf{7 , 7 1 9}$ & $\mathbf{1 0 0 . 0}$ & $\mathbf{7 , 5 2 2}$ & $\mathbf{1 0 0 . 0}$
\end{tabular}

* Other HEls = non-university HEls

Source: Authors' survey

Allowing for size of institution, the post-1992 universities are at the bottom of the mobility table (5.4 mobile students per 1,000 in 2002-03). This is because, for our responding institutions, the average size of the student body in the post-1992 group (about 18,000 students) was much larger than the average for the non-university group (about 4,000 students), and slightly larger than the pre-1992 group (about 14,500 students). The mobility rate in pre-1992 institutions was 11.4 per 1,000.

The survey also revealed that pre-1992 universities were better at retaining their European links (both through Erasmus and non-Erasmus schemes). This may be because they had stronger commitments to language-based mobility schemes, but it may also reflect differences in institutional policies. 


\section{The institutional perspective}

This chapter draws on two survey methods:

- questionnaire returns from $80 \mathrm{HEls}$ - see Annex B2 for an outline of this survey and for the questionnaire

- interviews with 46 academic staff and mobility managers in $10 \mathrm{HEls}$ - see Annex B1 for the selection of these sample HEls, Annex B7 for the interview questions and Annex B8 for the list of interviewees and their codes.

In contrast to the previous chapter, this one relies mainly on qualitative analysis. Two categories of primary evidence are presented:

- quotes from the written responses to the HEI questionnaire - these are set in italics

- extracts from face-to-face interviews with staff - these are set in normal type, followed by a code which denotes the interviewee and their institution (A-K).

Supplementary results tables from the HEI questionnaire are at Annex E.

\subsection{Managing mobility}

Two sets of forces frame the challenge of managing mobility:

a. The background institutional context, in particular the ways in which student mobility is prioritised within competing demands for resources and staff time.

b. Changing student characteristics and attitudes, including students' worsening financial situation, and the agendas for widening participation in HE. Evidence of this changing student 'supply curve' for mobility is presented at various points in this report.

Also two, at first sight paradoxical, statements run through the staff interviews and respondents' comments on the returned questionnaires:

- it is affirmed that (virtually) all students benefit greatly from the mobility experience: they become more mature, have higher employability, and get higher classes of degree

- it is lamented that many students seem unable to go abroad, for a whole host of reasons.

Are these last two messages really contradictory? We hypothesise that the apparent contradiction is related to a process of social polarisation, or at least increasing diversity, in the student population. In other words wealthy students can go, and benefit; but the majority find it more difficult to be mobile nowadays than in the past. Evidence to support this diagnosis is presented below and in Chapter 4 .

\subsubsection{Administering mobility}

The questionnaire survey showed that more than half of the HEls have a staff member with specific responsibility for outward student mobility; this proportion varies little across institutional types. In many cases - and especially in pre-1992 universities - there are separate persons dealing with European and with North American mobility. But in only a third of cases did the HEI claim to have a strategic plan for student mobility.

Data from the institutional questionnaire also reveal contrasts in the types of mobility between different categories of $\mathrm{HEl}$ (see Table 8 ). Note that this table measures total mobility initiatives $(n=364)$ ): each HEI had on average five such initiatives (this excludes Erasmus, IAESTE and language assistants). Mobility from pre-1992 universities was much more likely to be mandatory, to involve academic study 
rather than work placements, and to incorporate language learning. By contrast, mobility in the other $\mathrm{HEI}$ categories was more likely to be optional, to involve non-academic work, and to exclude foreign language learning. This reflects the somewhat different missions of different types of HEI, including the concentration of the 'academic' study of languages in the older universities, and the more vocationallyoriented character of the newer universities and other HEls.

Table 8: Typologies of outward student mobility initiatives (average = five initiatives per $\mathrm{HEI}$ )

\begin{tabular}{|c|c|c|c|c|c|c|c|c|c|c|}
\hline \multirow[t]{2}{*}{ Type of HEI } & \multicolumn{4}{|c|}{$\begin{array}{r}\text { Is mobility mandatory } \\
\text { or optional? }\end{array}$} & \multicolumn{4}{|c|}{$\begin{array}{r}\text { Does mobility involve } \\
\text { academic study at a foreign } \\
\text { HEI or work experience? } \\
\text { Work or mixture }\end{array}$} & \multicolumn{2}{|c|}{$\begin{array}{r}\text { Foreign } \\
\text { language } \\
\text { learning is an } \\
\text { intrinsic part of } \\
\text { the mobility } \\
\text { arrangement }\end{array}$} \\
\hline & $\sqrt{ }$ & $\%$ & $\sqrt{ }$ & $\%$ & $\sqrt{ }$ & $\%$ & $\sqrt{ }$ & $\%$ & $\sqrt{ }$ & $\%$ \\
\hline Pre-1992 universities $(\mathrm{n}=200)$ & 103 & 51.5 & 97 & 48.5 & 144 & 72.0 & 56 & 28.0 & 64 & 32.0 \\
\hline Post-1992 universities $(n=91)$ & 7 & 7.7 & 84 & 92.3 & 54 & 59.3 & 37 & 40.7 & 10 & 11.0 \\
\hline Other HEIs $(n=73)$ & 1 & 1.4 & 72 & 98.6 & 59 & 80.8 & 14 & 19.2 & 6 & 8.2 \\
\hline Total $(n=364)$ & 111 & 30.5 & 253 & 69.5 & 257 & 70.6 & 107 & 29.4 & 80 & 22.0 \\
\hline
\end{tabular}

Source: Authors' survey

\subsubsection{Strategies and tensions}

Surprisingly, only 34 per cent of HEIs in the survey had a strategic plan for student mobility. This needs further explanation. First, several respondents mentioned such a plan was in train. Second, in at least one third of all the cases where there was no specific student mobility plan; it was stated that student mobility statements existed within broader strategy documents - for instance in a European policy or international mission statement. Below is a typical example, from a post-1992 university in the London area:

'The University believes that the curriculum and student learning experience can only be enhanced through an exposure to international examples, to a second language and through participation in international exchanges. The University values and seeks to build further a multicultural environment for international, European and domestic students and staff, and our exchange programmes assist this ...

All students and staff from all departments within the university should be given the opportunity to experience an exchange abroad. To enable us do this, each department should establish and maintain international exchange partnerships with institutions with an ethos and place within their own domestic context which is similar to our own.'

Where HEls do have explicit strategies for ISM, they still conform to the kind of statement above. Remarkable is the lack of specific numerical targets for mobility: only 5 out of 27 cases. Here are two of these:

'The targets for student mobility were set in 2001-02 and will remain in place with the long-term goal of sending 10 per cent of all full-time undergraduate students (approximately 260 per year) overseas on an exchange programme. The figure currently stands at 5 per cent (not including short study visits).' 
'Increase number of outgoing students (outside EU) by 70 per cent by 2007-08.'

Tensions can arise in HEls over the issue of managing student mobility. Three administrative arenas can be recognised:

- the International or Study Abroad Office, whose staff may work full-time with mobile students and who have the deepest professional engagement with mobility

- academics in departments, especially those in positions of responsibility for mobility such as heads, Erasmus coordinators and work-placement tutors

- senior managers and administrators responsible for strategy and policy which might make reference to student mobility.

The first of these attracts much praise and appreciation, and very little criticism, according to our interviews. Academics are sometimes criticised for their lack of commitment and weak knowledge of the 'rules' of the mobility schemes. Senior management are often criticised for the lack of priority given to mobility 'from the top', and for not backing up fine-sounding policy rhetoric with concrete action and resources.

A common remark was that the institution did not have a clear strategy for international student mobility beyond the drive to recruit high-fee overseas students. Some senior managers interviewed were quite candid in admitting this was the case:

'Here's our Strategic Plan for 2003-2006 and I think it's quite useful because it shows you, essentially, that we have no strategy in this area (mobility). You'll see there's a section on overseas student recruitment - by overseas we mean non-EU - I think what we're saying is, if we're going to be investing effort, administrative effort in (say) North America, it should be in recruiting full fee-paying students ...' (H1)

Another senior administrator pointed to a void in the responsibility structure for student mobility in his institution:

'I think there is a bit of a void in the university in terms of, not strategy because we have our strategies, but I don't think on the Management Group there is a great interest in ... exchanges as such. There are other things that seem to be taking priority ... at the moment the message from the top is international recruitment and income generation. And for Europe we're just sort of bobbling along and I suppose that's why we're static in numbers of (exchange) students.' (J3)

\subsubsection{Departmental perspectives: priorities and imbalances}

Most student mobility initiatives have developed ad hoc at departmental level; as a result they have not been embedded in institutional policies on internationalisation. Nor is there much evidence of integration of student mobility within international research collaborations. At the departmental level, student mobility is rarely a prime concern. The exceptions are language and a few other departments where study or work abroad is intrinsic to the degree programme. Further limitations arise through lack of flexibility, or the imbalance in exchange student numbers.

These issues are exemplified in the following quotes. First, a Head of Geography:

'I have to say that, speaking as a Head of School, I really have not seen a need to get more students to go abroad. I've not seen it as one of the main driving factors of what I need to do as a Head of School. I think there are other more important pedagogic processes which are much 
more important for the 95-97 per cent who are staying behind ... and l've got to get that right. So it might just be that it's one of those things that if I had more time, which I don't, but if I had less demands ... I could identify this as being a key thing ...' (K1)

Where a university operates on a strict departmental basis, including responsibility for balancing student exchanges, complications can result, especially with language departments:

'The way the (Institution) operates, they simply want to see symmetrical exchanges between departments ... If we have an exchange with a French department, they don't want to send their French students here to study French, which is apparently what the (Institution) insists upon! ... People coming here want to do something outside the French department ... (but) that can be difficult to accommodate. We have to look around for what they can do, and get into deals with other departments ... Unfortunately the courses for which there is the greatest demand from foreign exchange students are those which are already bursting at the seams with our own students.' (A1)

Imbalance between in flows and out flows has obvious financial and administrative implications. All departmental staff interviewed referred to this important issue. For some departments the problem is structural and therefore virtually unavoidable:

'It has always been the case that there has been more students wanting to come ... than we have students going to Germany, for the very simple reason ... that many more students study English in most European countries, certainly in Germany ... than there are students here studying German. So it has always been the case of an imbalance ... and we don't really see any way of equalising it, given the circumstances.' (J2)

On the other hand, some science departments see the pay-offs to mobility as longer-term - for instance the recruitment of future postgraduate students. The following quote sets out a broader and less negative interpretation of the 'imbalance' problem.

'Science faculties like the (exchange) students ... they would want more of them and they are prepared to accept that there is some financial loss in not sending students out, but taking them in ... The Scientists are prepared to subsidise the imbalance because the students that they get in are good quality and some will stay on and graduate, or will come back for postgraduate studies ... It's difficult to recruit good science students ... so they see it as sort of enhancing the quality of their student body ...' (J3)

However, the problem of imbalance cuts both ways. With North American exchange schemes, the constraint is often the low numbers of incoming students. A pattern evident across many of the casestudy HEls sees a shift from European exchanges, which have been constrained by low outgoing numbers, to newer North American and Australian exchanges where the cap is from low incoming numbers. Typical is the experience of university $D$ :

'In 1993 our peak activities were in Europe; we had two or three American partners at that time. We were sending nearly 200 students to French- and German-speaking partners. This has now reversed. Now we are sending about 150 students for a semester or year abroad to North America, Australia and English-speaking Europe, and we are sending maybe 50 linguists for the compulsory year. We now have 30 North American partners, 3 Australian and about 10 in English-speaking Europe, where the teaching is in English ...' (D3) 
Exchange administrators note that UK students are especially attracted to exchange campuses in California, Florida, New Orleans and Australia. The climatic factor is all too evident. For exchangees moving the other way, a semester in an industrial city in Northern England or in Northern Ireland may be less appealing because of how these regions are sometimes perceived. Australian and Canadian students, in particular, are also put off by high costs. Moreover, many informants stressed that, whereas most UK students want to go to these long-distance Anglophone destinations for a year, most North Americans and Australians prefer to come to the UK for a semester.

\subsubsection{Rationalising exchanges, reorienting mobility}

Especially for European exchanges, declining numbers of mobile students, imbalances, and the historical proliferation of networks and partners are factors leading towards rationalisation of partnership agreements. Most of the $10 \mathrm{HEls}$ visited were engaged in this process. An example:

'When the Socrates task force was set up in this university, we did rationalise a lot of exchanges and told departments to re-thrash their existing arrangements to make sure that they kept those that would work and ... end any relationship that was not realistic.' (E5)

Many of the changes described above could be linked to the decreasing numbers of students coming through specialised language degrees and to the declining linguistic competence of non-language students. Hence the switch to North America and Australia as destinations. Some institutions have tried to respond to the student body's fall-off in 'linguistic capital' by preserving as many European destinations as possible but restricting placements to partner institutions or work environments where programmes are undertaken in English.

A good example of this pragmatic 'damage limitation' approach to sustaining European mobility is offered by institution B, a large, post-1992 university in London with a declining mobility profile.

'I would say we have recognised that we are no longer dealing with a student body which is fluent in European languages, except, of course, the local UK students of Greek and Italian origin. We are not talking about students who have A levels in a European language, so the student body is not one that is well-equipped (for mobility). We have insisted that our partners make it clear to us what programmes can be delivered in English and we advertise that to our students ... In some countries they will need some language skills just to cope with everyday life. We encourage students to go to countries where language is somewhat less of a problem for instance Spain ... We have sympathetic staff there and flexibility in the programme, enabling students to do something like a project module or dissertation delivered by the staff there in English and assessed in English, sometimes jointly by them and us ... In terms of identifying partners ... and finding a way round for the students who don't have linguistic competence, we can put together a programme which satisfies the needs of most of the students. Getting the message across is another thing!' (B1)

A broader-based pattern of expanding mobility links was evidenced in this detailed report from a pre1992 university in the Midlands:

'While the number of outgoing Erasmus students overall may have decreased slightly over recent years... the last four years has seen the development of a number of new mobility programmes giving students the opportunity to study outside of Europe, e.g. Australasia and North America. More degree programmes incorporating a period of study abroad have also recently been designed. Many schools have added a fourth year to their degree programme with the third year spent abroad, eg. Law with South East Asian Law (year in National University 
of Singapore) or Chemistry with a year in Australia. Steps have also been taken to encourage more post-graduate students to study abroad.'

This university's expansion of new schemes is in contrast to a neighbouring, also pre-1992, university, whose administrator responsible for Socrates coordination expresses a more cynical view:

'Participation in student mobility exchange schemes is largely for new student recruitment purposes: departments must be seen by new students to "have a student exchange scheme" with a good menu of potential links in place. Departmental strategy is "cover the bases" and limit overseas student intake (on exchanges).'

\subsubsection{Work placements and field trips}

Alongside a geographical reorientation of outward mobility, we found a growing preference for work placements rather than study abroad. One senior respondent of a post-1992 university wrote:

'It is generally accepted that overseas placements, particularly work placements, offer an excellent experience for our students and help them to focus on their future career plans. There appears to be a strong correlation between placement experiences and final Honours award classification. The main negative aspect of work placements abroad is the cost to the University of monitoring progress.'

Whereas most HEls engage in study-abroad exchange schemes which are centrally supported (although often departmentally administered) within the institution, work placements are generally less well-documented. International and exchange officers we interviewed generally knew little about such placements. They said they were not part of their remit and referred us to other staff, usually at departmental level, for the relevant details. Given that work-placement schemes were rare within our three 'target' departments (languages, maths and geography), our information about foreign work placements in the ten HEls we visited is rather patchy.

We can, however, make three robust generalisations:

a. Where students have the option of choosing work placements over study abroad, they tend to prefer the former because they are paid.

b. Many programmes with placements or sandwich arrangements do not offer specific foreign placements, so that work abroad may only be a tiny element in the overall scheme.

c. Work placements are more costly to administer than study-abroad schemes because they are often set up and monitored on an individual basis.

Interviews with academics in language departments revealed that paid language assistantships were making Socrates-Erasmus a 'second-choice' for many language students. Well-funded academic or work placements can also have the same dampening effect on Erasmus mobility. Annex $F$ looks at some successful non-Erasmus and work placement mobility initiatives in Northern Ireland.

Four interviewees, representing different HEIs, mentioned Leonardo-supported initiatives for work experience in science and technology. However, the scale was relatively small, although the potential for further utilisation was recognised. Concerns were expressed about the administrative commitment, with not enough financial support going to the students.

The issue of short-term mobility - study tours, field trips, foreign museum and gallery visits and so on also deserves comment. We would not want to view these academic travel experiences too lightly. 
However, it is difficult to think of them as constituting more than a brief exposure to another culture. For many such trips, their intrinsic interest and purpose lie in the material being studied - an ecological site, a library, archaeological remains - rather than in the wider culture of the area or country visited. The main exception to this rather dismissive judgement are geography field-trips, where the explicit aim is to study the landscape, settlement patterns, economic activities and culture of the target area. It was for this reason that we did some interviews with geography staff at the HEls visited. The following is a typical account of field-trip arrangements, including an example of how such trips can hook up with exchange partners.

'As geography students they have the opportunity to go on an overseas field course ... I think this is particularly important for geographers because we are trying to teach them about different parts of the world, their cultures and economic systems ... The venues vary, according to which options they are taking ... but they have to go on an overseas field course for at least one week. The physical geographers go to Almería in Spain and the human geographers go to Malta ... the university pays approximately half the cost and the students pay the rest ... There is a lot of work involved by academic members of staff; it is not a small task to take 40 or 50 students overseas and it is hard work logistically, as well as academically ... Sometimes we have used geography field courses integrated with the Erasmus or Socrates programmes. A few years ago I took one to the north of Sweden with geographers from some partner universities ...' (D2)

Without knowing the local language, however, foreign field trips have limited impact in terms of interaction with the local people and culture (Watson 2004).

\subsubsection{Other issues}

There are several other mobility management issues which we have collected information on and which can only be listed in passing here. Such issues include: problems of converting grades from different academic systems; questions about the quality of academic work in different countries; administering exchanges involving joint honours or modular degrees where simple inter-departmental exchange agreements do not suffice; the specific challenges of going abroad for mature students and disabled students; drop-out rates and 'escape-routes' from programmes involving mobility; and the way mobility is often used as a marketing tool to recruit students. Some of these issues are worthy of further systematic investigation.

\subsection{Drivers and barriers - staff views}

This section examines the 'drivers' and 'barriers' to student mobility through the eyes (and accumulated experience) of HEI staff. This is cross-referenced with students' views in Chapter 4.

\subsubsection{Benefits of mobility}

Respondents and informants saw mobility as unerringly positive and beneficial for students:

'There are substantial long-term benefits for participants (in the Study Abroad Programme).

These include a higher level of independence and development, and students who take part in study abroad achieve a higher percentage of first class and upper second class degrees' (pre1992 university, North of England)

'When they come back, they have developed, it's obvious - they've gained in confidence, they've matured, they really are different people. They say they have made friends that they are 
going to keep for life. They have looked at themselves differently, and they may even change their direction ... they may suddenly discover, actually that's not what I want to do with my life, I'm going to do something completely different ... But I also seriously think it helps employment prospects. I'm sure that employers are faced with hundreds of applications these days and anything that makes you stand out as somebody who has initiative and drive and confidence and adaptability - it's got to be of benefit.' (J4)

The key benefits identified or claimed have to do with personal development and maturity, cultural enrichment, language acquisition, better academic performance, and career enhancement. Similar endorsements, but talked up in a more student-friendly publicity genre, are found on HEI web-sites (see Annex G).

Several of the above quotes and those in Annex $G$ refer to the relationship between mobility and employment. We did not carry out systematic research on employers' and recruitment officers' attitudes to the benefits (or otherwise) of a period spent abroad by graduate job applicants. The evidence is therefore second-hand and anecdotal, coming either from the perceptions of students (described in Chapter 4) or from HEI personnel who have observed trends over a number of years and who may have links with employers.

Regarding academic performance, Table D15 in Annex D shows that Erasmus students are somewhat more likely to get a first or upper second (73 per cent) than non-Erasmus students (61 per cent). This may be due to positive selection, however; see below and paragraph 29 of Annex D.

Three further benefits were mentioned in the interviews. The first was the wider-scale inter-cultural impact of international student mobility - not just for the student but for society as a whole.

'Widening the range of countries students go to is the way we can break down inaccurate stereotypes. If you look at long-term international relations, the encouragement (to study or work abroad) is a sure way to make us understand other cultures and perhaps prevent conflicts ... Short terms of travel like holidays can sometimes reinforce the stereotype ... More long-term study and stays abroad enable you to understand what other societies are about.' (D4)

Second, much mobility was reciprocal, based on student exchanges. This means that the teaching and learning environment of departments with mobility schemes is enriched not only by those students who return from their stay abroad but, even more, by incoming exchange students:

'For the European Studies programme, it is definitely positive ... There are wonderful discussions going on in Europe-related subjects ... discussing the European Union together, giving a new perspective on Europe ... When they are all together in class, it is fabulous.' (A1)

The final issue relates to the potential spin-offs of mobility, especially bilateral exchanges and multilateral networks, into research and other aspects of universities' international work. This next interview extract stresses the international recruitment aspect:

'Where the Year Abroad is concerned, it helps our profile in the USA, Canada and Australia. We don't have many fee-paying students and it helps us with our promotion in those areas. If a student comes on a short-term placement, they might come back and do graduate courses and PhDs ... Erasmus is the same ... It's very good for recruitment as Erasmus students often come back to do a Masters and turn into EU fee-paying students.' (E4) 
Synergies between student exchange schemes and staff research collaboration depend on individual links and personal circumstances. The view that student exchange bolsters or results from international research collaboration seems to be one held by administrators and is less often borne out at departmental level, as this head said:

'Research links don't map directly onto Erasmus exchanges ... The schemes have grown up through long-standing personal links ... The way Erasmus tends to work is not conducive to maintaining research links ... It doesn't work like that ... You either maintain the research link without Erasmus, or the other way round.' (G1)

\subsubsection{Profiling the mobile student}

Four generalisations recur about mobile students in the interview narratives. They are:

- more ambitious, outward-looking and self-confident

- positively selected academically

- from middle-class backgrounds

- disproportionately 'non-local' or 'foreign'

These points will be exemplified in interview extracts below. In order to bring out the institutional and regional perspectives, we concentrate on three HEIs. These are a large post-1992 university in London with an ethnically diverse student body (B); a pre-1992 campus university in the Midlands (D); and one of Scotland's main city-located universities (J). (Students at the Scottish institution are traditionally nonmobile.)

First, some comments from university D:

'I would say we have a mixed group of students ... Because we recruit locally, nationally and internationally, we have the most diverse student population on our campus ... I don't really know if the ones who choose to do a year abroad are typical of the university's social composition, I don't think we have that sort of data on them ... I would assume they would be more middle-class because they can make the money available ... Grade-wise, we set a minimum 50 per cent average which $1^{\text {st }}$ years must pass to go -40 per cent is the pass mark here, so just passing is not enough ... Individual departments may set higher criteria - Business Studies, 55 per cent, or you don't go ... Economics, 60 per cent or they will not let them go ... We send a whole range of students out, but not the very weak ones and probably not the very brightest ones as they will see it as a risk.' (D3)

Another colleague spoke of more personal factors, the changing recruitment base of the university, and the reluctance of the 'local' students to go abroad:

'It does take a certain personality type with a bit of "get up and go" to go abroad for six months or a year. For example in France, they don't look after students and give pastoral care ... you have to have a certain amount of resilience. I think the English universities are sometimes "over-caring" in making students feel at home ... There is also the financial dimension. Students from a more wealthy home find it easier, as their parents may foot the bill for what they consider is a good idea ... According to the statistics, we are recruiting more local students now, and less from other parts of England ... I don't think this area is very conducive to the idea of migration! The people here are quite "local" and there is no evidence of any migration, perhaps because of the specialised industries here. That is my impression as regards the students' outlook. These are people who are "first-generation" university students. They feel they have already made a 
big step by coming to university! If you are a student from the South East or South West then you are more used to the idea of mobility. A lot of people from other parts of the country have travelled quite a lot already so they have a different attitude to mobility.' (D1)

This last point was made with even more force by the staff interviewed in the other two universities. In university $B$,

'one trend that we have noticed is that those most willing to travel are non-UK based students, so we import students from Finland, Greece, wherever, and they will travel. To get a student from north London to travel is really impressive!' (B1)

His colleague provided more details in her interview:

'We have a higher proportion of foreign students going abroad from here ... we have students from all over Europe who want to go and they have better language skills ... A lot of our students live at home and ... are ... from fairly deprived backgrounds. They live at home for financial reasons and the Asian students live at home with protective parents ... they need reassurance ... The students with the non-standard entries are the hardest to shift, and they need it most. It would give them confidence and allow them to stand out from the mass of other graduates.' (B4)

But ethnic-minority UK-based students are not always reluctant to move, as shown by the predilection of Afro-Caribbean students to go to the United States:

'... we find ... the Afro-Caribbean students are quite keen on exchanges. They have a preference for going to the United States, for obvious reasons I think. We have a specific exchange programme. While not exclusively limited to black students, we have partners in the southern states in black universities ... With the Asian group, slightly less - not a great interest here. It also depends on the subject a lot. If you went to the Social Sciences and Arts/Humanities areas, the Black/Caribbean numbers are higher than those of the Asian populations. Here in Computing Sciences, there are quite a few British Asians. But Computing Science students, for one reason or another, tend not to take up exchanges.' (B1)

The interviewees in university $\mathrm{J}$ concurred that Scottish students, particularly those who live locally and at home, had a low propensity to undertake study abroad, at least during their degree programme. Here are two interview clips from 'mobility managers':

'... we're dealing here with sort of quite conservative students. We get a high percentage from the West of Scotland, a lot live at home ... they feel they are not ready ... What they do is they graduate and then they go and they travel for a year ... A lot of the students who go on exchanges are actually the ones who've come up from England, you know ...' (J3)

'Compared to even the other Scottish universities, ( $\mathrm{J}$ ) has always had a local catchment - a high proportion of local people ... For a while it was really obvious that the students we were sending abroad were all English. And when you think about it, they've already had the confidence to leave home, you know, make that step and not be near their mother, and whatever, and obviously, they've got the financial backing to do it. It costs a lot, in Europe possibly less so, but everywhere else it costs a lot. I mean... Scottish students don't have thousands of dollars sitting in their bank account.' (J4) 


\subsubsection{Deterring factors}

By drawing up a composite identikit of mobile students in the previous section, we have already given clues about the barriers to student mobility as seen by HEI staff.

Four key deterrents stand out. In order of importance they are:

- financial problems

- language barriers

- institutional constraints

- student attitudes.

The issue of finance has many ramifications. It refers not only to shortage of money and indebtedness, but links also to the class background of students, student lifestyles (in particular, part-time employment), and issues for the future such as university fee regimes. Although not all the interviewees felt able to rank the various deterrents, where they did approximately twice as many nominated finance as the key factor as those who thought language to be the main obstacle to outward mobility. And on the open-ended comments on the HEI questionnaire, 30 respondents out of 80 mentioned financial issues and 14 highlighted language barriers.

The first quote covers a number of issues that echoed, in various degrees, through many of the staff interviews:

'I think students are increasingly de-motivated by financial concerns. Students are increasingly motivated by the desire to get a degree, get a job and move on. And they do perceive a year abroad as an extra, even though the whole point of the Erasmus exchange is that it is built into their degree ... They worry about leaving behind a part-time job, or a virtually full-time job in some cases, that's the reality of it ... It could be difficult for them to get employment abroad, and then come back and have to find work again. And I think it's parental pressure as well ... when parents are already paying out increasingly to support their offspring at universities, it's not necessarily something they want to encourage their offspring to do.' (H1)

The linked issues of financial pressures and part-time employment surfaced repeatedly:

'For a lot of the students cost is a major factor: not so much the cost of the visit ... or actual cash-in-hand - it is the jobs. They have a part-time job, but can't afford the risk of losing it when they come back. I think class enters it in that way. At this university we don't have a large number of middle-class students, which means our students are less familiar with travelling ... The hard economic facts are crucial ... they are coming back half-way through their second year and are probably sacrificing a cheap flat and a job for the rest of their stay.' (B1)

Second, language is key to mobility, especially within Europe. The problem of UK students' generally poor, and declining, knowledge of foreign languages is a recurring theme in the discussion about UK student mobility. Although our evidence suggests that language takes second place to financial barriers, in other respects the comparison is not straightforward since the language issue impinges in different ways and at different points in decisions about mobility. There is the backdrop issue of declining interest in language learning in schools, shown by falling rolls at GCSE and A-level in most languages, and by the downgrading of languages in the secondary national curriculum. This feeds through to applications for language degrees in $\mathrm{HE}$ and possible shifting balances between languages as a 'major' or 'minor' part of degree programmes. The language issue seems to contribute to the shift of interest from European destinations to Anglophone environments in other parts of the world. 
Some of the most detailed evidence on these themes comes from academics working in language departments. Here a departmental head of a pre-1992 university presents his analysis of recent trends.

'There has been a wind-down of languages ... and therefore those having the linguistic skills to be able to go abroad. There has been a fall in those taking the Erasmus migration route ... Languages are now recognised as being difficult, and that has a knock-on effect (on mobility) ... though Spanish has gone against the trend. Russian has become very small, it's quite worrying. Italian has been holding its own ... we have a community in (name of city) supporting the language because of family connections. French and German are perceived as difficult languages to learn. They (the students) believe Spanish is easier - at the early stages it probably is, the difficulties come later. Many of our students believe that Spanish is "sexy" flamenco dancing, tapas bars etc... Also many go on holiday there and are influenced by what they find, they want to get in on the lifestyle. South America also comes into the picture students see it as an area where they can go to "help out" with their idealistic motivations ... All of this comes into the context of today's students' way of thinking, and that is where French and German have suffered. Once, in the business world, it was felt you had to have these two languages. There has been a great change in perceptions.' (J1)

The post-1992 universities have been affected by the decline in language programmes, a fact that helps to explain their poorer performance on mobility trends compared to other HEls. The linguistic skills many of their students have, which reflect their family ethnic origin, do not match the languages taught at the institution or the destinations on offer. This somewhat rueful quote from a student exchange coordinator at a post-1992 university in London expresses both despair at the fall-off of language and exchange activity, and envy for what appears to be the situation in certain other universities.

'Yes, we have a huge problem. We cut our language staff ... If we were rich and attracted middle-class students who had been abroad a lot, that would be different. At a European Officers' meeting, someone from (name of university) said they had no problem sending students, because their parents had houses in Tuscany and they went abroad all the time. A lot of our students ... have non-standard entry backgrounds ... we have more of those than other universities ... A lot of our students speak Asian or immigrant languages ... Punjabi or Urdu, we are now getting students who speak Arabic, and in these countries we have no links ... The difficulty is we have more links than students going abroad, so it's difficult to spend time creating new links.' (B4)

The third deterring factor is institutional and academic barriers. According to a Dean of an Arts Faculty, an important reason for non-mobility is

'generally, a disruption to their studies, moving from one system to another. Even those who come back experience some sort of disruption. There is also the difficulty of finding a compatible programme. We are fairly flexible on what counts - in History, for example, on what period you take or what country - but in Psychology, which is a more linear subject, there have been restrictions ... and you have to do certain things which require certain techniques, and there is a problem in finding suitable partners.' (D1)

One mobility officer pointed to the problem of academic staff discouraging good students from going abroad for fear of jeopardising their degrees: 
'There are staff out there ... who will discourage good students from going away because they will lose them from the classroom and because - I mean, it's a myth - but they feel that the student may risk their chances of getting a First or a 2.1 if they're borderline ...' (J3)

Further problems relating to the regulated nature of the UK academic system were raised by several respondents. Specific reference was made to the shorter and more rigid nature of UK degrees, and to the uneasy relationship between quality assurance and foreign study or work experience. It remains to be seen how the creation of a European Higher Education Area (as a result of the Bologna Process) will affect the structure of UK degree programmes, and how mobility patterns will change.

Fourth on the list of deterrents is student attitudes. This is a nebulous area which covers a variety of explicit or nuanced feelings to do with lack of confidence, attachedness to home, fear about the unknown, worries over the academic impact of studying abroad and so on, and is considered in Chapter 4. Academics and mobility managers have also observed this syndrome among their students.

Part of this concern has to do with what one interviewee called 'academic scarediness': what students fear they will lose out on. These include the risk of low grades from the 'unknown, foreign' university, missing important courses at their home university, and, if they are away for a year on an 'optional extra' mobility scheme, coming back to a cohort of students whom they don't know. Meanwhile their original peers will have already graduated.

'Academic scarediness - "what will I gain, will this harm my degree result? I need a 2.1 - if I go abroad I may harm this" ... British students have the concept of a package holiday - everything has to be done and rolled up. That's not how the Swedish, German or French student thinks ...' (D3)

'I certainly get people who say, I don't want to graduate a year later than all my friends. I'll come back and be here, you know, and I wouldn't know anybody. So that peer group thing is certainly there ... Often they're anxious, they want to get on and get a job and pay off their debts ...

Others will express a concern ... that they will be missing out on courses here that their contemporaries are doing, they are worried that they would not be able to catch up.' (K2)

A final dimension of students' negative attitudes towards mobility has to do with the strength of their local and regional connections within the UK. This lack of cosmopolitanism appears to be most deeply entrenched among Scottish and Northern Ireland students.

\subsubsection{Concluding points}

The topic that many returned to in their final remarks was the language dimension. The general feeling was one of exasperation, but also resignation, about the foreign languages scenario in the UK. The possibility of starting languages in primary school was welcomed, but this 'step in the right direction' was counterbalanced by the 'two steps back' of downgrading foreign languages in the national curriculum, where it is no longer compulsory at GCSE. This, according to one interviewee, 'sends out the signal that languages are not important'. While some interviewees interpreted these language trends as closely linked to their own institutions' future prospects for student mobility, others linked them to prevailing UK discourses of Euroscepticism. Annex $\mathrm{H}$ contains a sequence of quotes on this issue. 


\section{The student perspective}

To capture the student perspective, we report here the findings of a questionnaire survey of 1,200 students as well as interviews with students selected from $10 \mathrm{HEls}$ spread across the UK. Chapter 1 and Annex B provide details of the survey tools and methodology. Table 9 profiles the student respondents, and Annex I contains further background data. In the subsections which follow, we first compare the characteristics of mobile and non-mobile students. We then contrast the perceived benefits and problems of mobility. The results build towards a better understanding of students' views of the drivers and barriers to mobility.

The questionnaire and interview surveys showed that mobility during higher education is only one feature of a much wider mobility culture. Most students had opportunities for foreign travel before coming to university, such as family holidays and school exchanges. Many had taken a gap year. Equally, during HE many students participated in a short foreign visit organised by their departments especially the geography students. And many students saw opportunities for foreign travel or work after university.

In presenting interview evidence, each quote is suffixed by a code which denotes the institution of the respondents (A-K), the sex of the student ( $m$ or $f$ ) and their course of study (geography, maths and so on). If no further notation is given, they are non-mobile students. For those who had been abroad, the destination is given. The vast majority of interviewees were aged 20, 21 or 22.

Table 9: Student interviewees: profile characteristics

\begin{tabular}{lrrr}
\hline Characteristics & First year & Final year & All respondents \\
\hline Average age & 19.0 & 21.4 & 20.2 \\
\% Female & 54.8 & 61.3 & 58.1 \\
\% EU students & 4.7 & 2.3 & 3.5 \\
\% Overseas students & 2.2 & 1.3 & 1.7 \\
\% White UK/Irish & 81.6 & 88.4 & 85.1 \\
\% 'Other' White European & 5.3 & 4.9 & 5.1 \\
\% Father's occupation 'Professional or managerial' & 51.0 & 53.4 & 52.2 \\
\% Father with university education & 31.3 & 32.8 & 32.0 \\
\% Living in university halls of residence & 59.2 & 12.0 & 35.6 \\
\% Financing by loans & 73.0 & 78.7 & 75.8 \\
\% Receiving a parental contribution & 55.5 & 54.0 & 54.7 \\
\% With a term-time job & 40.4 & 52.3 & 46.4 \\
\hline
\end{tabular}

Source: Authors' survey

\subsection{Movers and non-movers}

Some 35.5 per cent of final-year students in the questionnaire survey had studied or worked abroad during HE. This mobile group included two contrasting types of students (see Table 10). One type (language students) went abroad as a compulsory element of their studies. The others (the science and social science students) were mostly self-motivated movers 'choosing' to go abroad for a range of personal, educational and professional reasons.

Among those who had been away for a term or longer, 59 per cent had been on Socrates-Erasmus exchanges. Other forms of international mobility captured by the sample included the British Council language assistant programme, work placements, institutional exchanges between specific universities, 
BUNAC and a range of other channels of movement. The majority of institutionally organised exchanges were between UK and US universities.

Table 10: Mobility rate for final-year students by subject area

\begin{tabular}{lllrr}
\hline Faculty & $\begin{array}{l}\text { Total no. of } \\
\text { subject area }\end{array}$ & students per & $\begin{array}{r}\text { Mobile students per } \\
\text { subject area }\end{array}$ & $\begin{array}{r}\text { Mobility rate per } \mathbf{1 , 0 0 0} \\
\text { students }\end{array}$ \\
\hline Language & & 200 & 191 & 955 \\
Science & 200 & 10 & 50 \\
Social science & 200 & 12 & 60 \\
\hline Total & $\mathbf{6 0 0}$ & $\mathbf{2 1 3}$ & $\mathbf{3 5 5}$ \\
\hline
\end{tabular}

Source: Authors' survey

The dominance of language students in the overall pattern of mobility had a clear effect on the destination countries to which students had gone. France was the most popular destination (44 per cent). Science and social science students were very different; here the US accounted for 41 per cent of mobility.

Table 11 shows that mobile students had a much higher rate of language proficiency. This is partly explained by the number of students for whom language constituted the core element of their studies. But it was also important in distinguishing between movers and non-movers among science and social science students.

Table 11: Relationship between language proficiency and having been abroad (final-year students)

\begin{tabular}{lllll}
\hline & $\begin{array}{l}\text { Proficient in } \\
\text { speaking a foreign } \\
\text { language }\end{array}$ & $\begin{array}{l}\text { Not proficient in } \\
\text { speaking a foreign } \\
\text { language }\end{array}$ & $\begin{array}{l}\text { Total } \\
\text { la of students } \\
\text { proficient in } \\
\text { speaking a language }\end{array}$ \\
\hline Studied abroad & 194 & 19 & 213 & 91.1 \\
Did not study/work abroad & 103 & 284 & 387 & 26.6 \\
\hline
\end{tabular}

Source: Authors' survey

Language proficiency was not only a factor explaining differences of behaviour between movers and non-movers. It also was an important predictor of intention to move by first-year students. Nearly 70 per cent of first-year students who definitely wanted to go abroad were proficient in speaking another language (see Table 12). Although the figures in the sciences and social sciences (in other words, excluding language students) are lower, the same trend is found.

Table 12: Relationship between language proficiency and the intention to go abroad (first-year students)

\begin{tabular}{lrrrrr}
\hline $\begin{array}{l}\text { Intention to go } \\
\text { abroad for } \\
\text { study or work }\end{array}$ & $\begin{array}{r}\text { Proficient in } \\
\text { speaking a } \\
\text { foreign } \\
\text { placement }\end{array}$ & $\begin{array}{r}\text { Not proficient } \\
\text { in speaking a } \\
\text { foreign }\end{array}$ & Total & $\begin{array}{r}\text { \% proficient in } \\
\text { speaking a } \\
\text { language }\end{array}$ & $\begin{array}{r}\text { \% proficient in } \\
\text { speaking a } \\
\text { language }\end{array}$ \\
\hline Definitely & 165 & 75 & 240 & 68.8 & language (science \\
Perhaps & 87 & 153 & 240 & 36.3 & 39.5 \\
No & 26 & 67 & 93 & 28.0 & 32.4 \\
Don't know & 6 & 20 & 26 & 23.1 & 24.4 \\
\hline
\end{tabular}

Source: Authors' survey

Note: In this and subsequent tables students who did not answer the question are excluded from the figures. 
Among non-language students, many other factors differentiated movers from non-movers. Females were more likely to go abroad than males. Those with a mother or father in professional and managerial employment were more likely to migrate; this probably reflects their educational and class background as much as any direct financial driver of mobility. Non-language students who had a mother or father with university education were about 50 per cent more likely to take up opportunities to study or work abroad. 'Visible' ethnic minorities had a lower mobility rate than white UK students, but students with other 'white' ethnic identities were highly mobile. Annex D reveals that about 12 per cent of all students on outward Erasmus exchanges are non-UK nationals.

Both the questionnaire survey and the interviews confirmed the link between an individual's mobility history and their likelihood of engaging in student mobility. Participation in foreign school exchanges and gap years were strong predictors of ISM. Some 21 per cent of respondents had taken a gap year. Of those who had been abroad, the experience had raised their desire for further international experience during their HE studies. Only a tiny minority appeared to have used their gap year as a substitute for a year abroad while at university (see Table 13).

Table 13: The influence of a gap year abroad on students' attitudes to spending time abroad during their studies

\begin{tabular}{lrrrr}
\hline \multirow{2}{*}{ Gap year } & \multicolumn{2}{r}{ First-year students } & \multicolumn{2}{r}{ Final-year students } \\
& No. & \% & No. & \% \\
\hline Decreased the likelihood of a year abroad & 3 & 4.8 & 4 & 6.7 \\
No effect & 13 & 21.0 & 15 & 25.0 \\
Increased the likelihood of a year abroad & 46 & 74.2 & 41 & 68.3 \\
\hline Total & $\mathbf{6 2}$ & $\mathbf{1 0 0 . 0}$ & $\mathbf{6 0}$ & $\mathbf{1 0 0 . 0}$ \\
\hline
\end{tabular}

Source: Authors' survey

\subsection{Perceived benefits and problems associated with mobility}

Most students felt very positive about their study/work placement abroad. Indeed 92 per cent of language students expressed themselves as 'satisfied' or 'very satisfied' with their time abroad. Satisfaction ratings were even higher for the smaller number of social science and science mobile students.

The reasons for these positive views were explored by a set of attitudinal questions (see Table 14). On professional, educational and personal criteria, the mobility experience was perceived very positively. For instance, 95 per cent of students felt the experience enhanced their personal development, and 90 per cent felt that it was relevant to the development of an international career.

Table 14: Percentage of students who felt that the period spent abroad had been worthwhile or very worthwhile relative to a range of criteria

\begin{tabular}{ll}
\hline Criteria & $\%$ \\
\hline Understanding of another country & 99.5 \\
Maturity and personal development & 95.3 \\
Relevance to developing an international career & 90.2 \\
Foreign language proficiency & 87.9 \\
Enhancement of academic and professional knowledge & 83.2 \\
New way of thinking about the home country & 83.2 \\
Relevance to employment prospects & 76.2 \\
\hline
\end{tabular}

Source: Authors' survey $(n=214)$ 
Interviews yielded more nuanced accounts. The main benefits were seen in the social, cultural and linguistic realms; academic benefits were stressed less often. A typical quote:

'... living in a different country, that was really good, meeting new people, the fact that you have to speak the language all the time, that was really important; travelling, we did a bit of travelling as well. It was just really an overall good experience, I think.' (D - $f-$ German and applied social sciences - 1 year in Germany)

Mobile students struggled to identify any major problem with their time abroad. In the questionnaire survey, no single factor was listed by even a quarter of students as problematic (see Table 15). Some found finance a problem, others being separated from their boyfriend/girlfriend.

In the interviews, likewise, negative aspects were few and infrequently cited. Mainly students referred to the problems of settling in at the start of their stay abroad, some difficulties adapting to the new academic system, and making host-country friends.

Table 15: Most problematic aspects of living abroad as expressed by students who had been abroad

\begin{tabular}{lr}
\hline Problematic issues & $\%$ \\
\hline Not enough financial means & 22.3 \\
Away from boyfriend/girlfriend & 20.0 \\
Language & 14.0 \\
Distance from parental home & 8.9 \\
Commitment to partner & 8.2 \\
Living in another culture & 8.2 \\
Studies not recognised & 4.9 \\
\hline
\end{tabular}

Source: Authors' survey $(n=214)$

Socio-economic background, not surprisingly, influenced perceptions of financial difficulties while abroad. Students financed totally by their parents were the least likely to face problems while abroad (64 per cent in this category found finance unproblematic). By contrast, 67 per cent of those depending entirely on loans or other ways of self-financing had financial problems while abroad.

\subsection{Drivers and barriers to international student mobility}

Both final-year students who had not been abroad and first-years who were not planning to go abroad offered suggestions for their immobility. Results from the two sets of questionnaires are presented in Figure 4 and the statistical base is in Annex I.

We refer to the pair of graphs in Figure 4 throughout the ensuing analysis, supported by further tables and interview extracts.

\subsubsection{Financial factors}

Figure 4 shows that lack of adequate finance is the factor most frequently cited by final-year students as a 'very important' contributor to their decision not to go abroad. Non-mobile students tend to see financial factors as much more problematic than mobile students (see Table 15). This raises the possibility that some respondents 'declare' financial factors to 'hide' other, perhaps more personal reasons. 
Final-year students

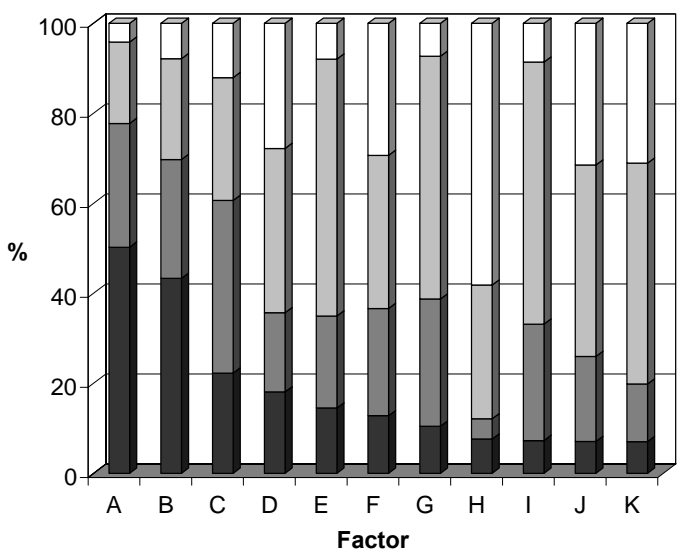

$A=$ Not enough financial means

$B=$ Not confident enough with the language

$\mathrm{C}=$ Insufficient information on possibilities to go abroad

$\mathrm{D}=$ I have (had) a boyfriend/girlfriend

$E=I$ would have had to prolong my degree

$\mathrm{F}=$ Studies not recognised

$G=$ Wary of living in another country/culture

Source: Authors' survey
First-year students

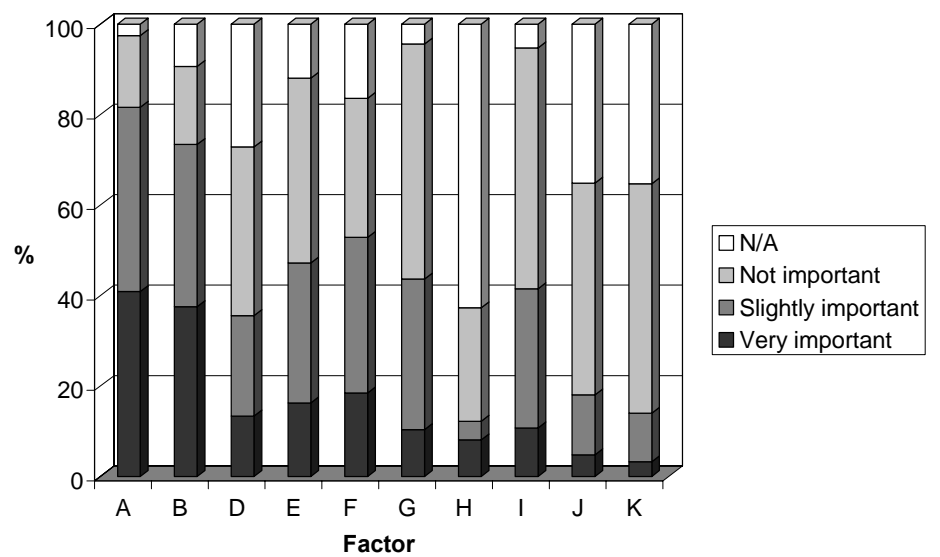

$\mathrm{H}=$ Commitment to partner and/or children

$\mathrm{I}=$ Difficult to leave parental family

$\mathrm{J}=\mathrm{I}$ (would have) had to leave my job

$\mathrm{K}=\mathrm{I}$ (would have) had to leave my flat

$\mathrm{N} / \mathrm{A}$ refers to students who answered the question but who judged the factor as being 'not applicable' in their specific situation.

Abundant interview evidence documents the (perceived) financial aspects of mobility. The fact that many students nowadays work, or are highly dependent on parental help, or on loans, was raised by many students, as were expressions of concern over increasing university fees. Implicit in many of the students' comments was the perception of mobility as an elite phenomenon. Three examples illustrate these issues; note that one reflects the mature-student perspective.

'... university is nowadays very expensive and with the prospect of top-up fees and increasing university cost, I think that it is very likely that fewer and fewer students will have the financial means to even think about going abroad ... also many students, like myself, work nowadays ... which makes things more difficult ... I think the government ought to put more money into helping those students who need or want to go abroad.' ( $C-m$ - Journalism)

'... money is probably a factor; actually university is already quite expensive, so there is massive debt involved with going to university nowadays, so if you are adding a thousand or two thousand to that to go to study abroad, then it probably does limit it to certain students ... other students might not be able to go because of financial restrictions.' ( $D-m-$ Psychology and biology)

'... Given the current context of increasing cost of university and life in general, in addition to low wages, expensive housing ... you know, many students have to work nowadays to support themselves through university, like myself. So, I think that the issue here is money, really ... especially if you're a mature student, or from a socially disadvantaged background.' ( $F-f-$ Maths - late 20s) 
As we will see later, the question as to how useful a period of study abroad might be was often answered in academic terms. A number of students put the cost of study abroad in perspective to its academic value. And some questioned the latter: In the words of one interviewee: 'Frankly speaking, it looks to me like an expensive form of academic tourism'.

\subsubsection{Language factors}

The second most important inhibitor for non-mobile final-year students was language. Over 40 per cent saw this as 'very important' and a further 26 per cent as an 'important' reason for not going abroad.

Most interviewees pointed to the general lack of foreign language knowledge as a key deterring factor. Some were worried that the study of a foreign language might be seen as unrelated to the core subject, or blamed the lack of foreign language opportunities in their degree programmes.

'When you do subjects like Maths you're not given the possibility to do languages ... at least I don't know anyone here who does them. Also, the fact is that the range of courses you do does not have any relationship whatsoever with foreign languages ...'(F-f - Maths $)$

The issue of foreign language knowledge is related to a broader 'fear of the unknown':

'I probably reckon it's the language barrier - you just don't have the basic skills in order to grasp a foreign language, and that's a massive confidence thing. If you are very sort of lost in their language and you think that you can't get by ... I think that's the main barrier.' $(\mathrm{H}-\mathrm{m}-$ Geography)

Many interviewees made comparisons to other countries in order to emphasise this issue:

'I think it's probably an aspect of confidence, you know. You talk to European students studying here and they've all done numerous languages at school from a very early age, whereas you look at our schooling system and languages are not that important ... I'm sure this is a barrier against people going abroad to study.' (H - m - Geography)

The language issue was connected by some students with the need to choose those subjects at A-level which would get the best grades. Languages lost out:

'I think a big problem is the language, that no one has any confidence in their language. When you're at school it's like not cool to learn a language; it's not promoted, really. And then when you go to A Level, even if you're kind of interested, unless you're really good, you don't take a language, because you have to get your A Levels to get into university. I think you have to pick your best, best, best subjects; even if you have a really good interest you don't even have a go.' ( $G-f-$ Maths)

The language issue also came across later in the interviews, when we invited students to suggest areas of action to increase the numbers of students involved in mobility. Many interviewees, especially the non-movers, emphasised the need to enhance the teaching of foreign languages at school.

'I think from the language point of view the best thing they can basically do is to teach ... a grasp of a foreign language at a lower level at school, you know, kind of bring it through in primary school. Because then if you learn a foreign language all the way through, I think you get to the point where you can speak it very, very clearly and you're confident with it. So, I think that this would encourage more people to go.' ( $\mathrm{H}-\mathrm{m}-$ Geography and management) 


\subsubsection{Information factors}

The third most cited reason for not going abroad was 'insufficient information on possibilities to go abroad'. Nearly 60 per cent of final-year respondents thought this was 'important' or 'very important' (see Figure 4). Further evidence on this issue is in the first-year questionnaire results: 47 per cent of respondents claimed to have heard of the Socrates-Erasmus scheme. Knowledge of Erasmus was especially low among non-language students - less than a third of whom had heard of the scheme. Only 21 per cent had heard of any other national or institutionally-led schemes; BUNAC, Leonardo and university-specific exchanges were cited.

Many non-movers interviewed highlighted lack of information as an important deterrent.

'The thought had crossed my mind but I didn't know enough about it or what opportunities there were ... I had the idea that it would be quite an interesting thing to do but I didn't know enough about it to ... you know, have a look at it seriously.' ( $E-m-$ Maths)

Several students referred to the timing of promotion, indicating that appropriate information ought to be given earlier, even in schools.

'I only got sort of very sketchy information. I think it was either during the first or second year there was mention of meetings you could go to, sort of after the lectures or at a certain time, where you would have a talk by someone about what was on offer, but it wasn't compulsory to go to these. So, it wasn't really promoted ... you kind of forget about it.' ( $F-m-G e o g r a p h y)$

' $\ldots$ it's about going into the schools, and starting there to promote it ... and get them young, I think. Because then their mentality is different. They should get students who have been on a year abroad going themselves into schools and talk to the pupils.' (B $-f-$ Nursing - Finland)

\subsubsection{Attitudinal and socio-cultural factors}

Figure 4 indicates that no other factors were considered inhibitors of mobility by more than 20 per cent of respondents. However, from the interviews insights emerged about people's (and their families') attitudes to studying abroad. Some drew attention to broader cultural factors within British and Northern Irish society. The following extracts exemplify some of these mutually reinforcing relationships.

'I get the impression maybe that, not myself, but maybe Britain itself thinks of itself quite as an individual country that isn't European, isn't American, it's kind of in between ... and specially in Scotland, it's kind of insular sometimes ... one of my friends laughed at me - my Belgian friend laughed at me when I told her that I was going to go to the "continent" ... she was like mocking me for saying the "European continent" ... but that's how it's thought ... I think being like isolated, as an island, makes it a bit different.' ( $\mathrm{f}-\mathrm{f}-$ Geography)

'Because here, I think, within the Northern Ireland context, people don't travel. It's not normal, people don't travel here. People who tend to travel, they go to Marbella for two weeks and they think they travel. My parents, when they see me travelling, they say "Why? Don't go".' (K - m Languages - Year abroad as language assistant in Spain)

This qualitative evidence is interesting and revealing. But it should not be exaggerated, particularly in light of the fact that such views are not necessarily statistically significant in accounting for differences in student mobility behaviour. 


\subsection{Further comparisons}

Figure 4 provides parallel data for first-year students. Financial factors and language concerns once again top the list, although fewer saw them as 'very important' compared with final-year students. For first-year students the third most important factor is the belief that study abroad may not be recognised for their UK degree. Nearly one-fifth of respondents felt this was very important, and this was backed up by interview evidence. These concerns may be unfounded.

It is useful to compare mobile and non-mobile student perceptions of various 'mobility inhibitors' as a means of trying to understand the drivers and barriers to international student mobility. Table 16 compares final-year students in the sciences and social sciences who went abroad with those who did not, identifying statistically significant differences of view.

Four very significant differences are apparent. First, students did not want to go abroad if their home institution did not recognise the course of study. Second, they were reluctant to go because of the perception that this meant prolonging their studies. In practice this perception is misplaced for most students. Although most of those taking languages add a year to their studies, other students engaging in Erasmus complete in the same time as their peers. Third, mobile students were the ones who were most confident of their language skills. And fourth, mobile students were much less likely to be worried about the financial implications than their non-mobile peers.

Table 16: Comparison of views of factors inhibiting mobility between mobile and non-mobile final-year science and social science students

\begin{tabular}{ll} 
Inhibiting factor & Statistical significance of difference \\
\hline Not confident with the language & Very significant \\
Difficulty leaving parental family & Not significant \\
Wary of living in another country & Not significant \\
Boyfriend/ girlfriend & Not significant \\
Partner/children & Not significant \\
Not enough financial means & Very significant \\
Studies not recognised & Very significant \\
I had to leave my flat & Not significant \\
I had to leave my job & Not significant \\
Prolongation of degree & Very significant \\
\hline
\end{tabular}

Source: Authors' survey

See Annex I Table 143 for details of the tests on which this table is based.

\subsection{A model for student mobility}

The drivers and barriers to mobility evident in the student survey are summarised in Figure 5 below. The model does not attempt to represent national, international, institutional or departmental factors reviewed elsewhere in this report. We see these factors as key drivers of mobility, but ones that lie 'outside the box' of student decision-making.

What Figure 5 indicates is that, for individual students, several drivers seem to be important in encouraging them to consider mobility. There are equally many forces discouraging movement: the barriers in the model. For students 'inside the box', specific profile characteristics (such as gender, socio-economic background, previous mobility history) can either increase or decrease their likelihood of responding positively to the drivers of mobility or negatively to the barriers to movement. 
Figure 5: A model of the student decision-making process (after Morgan 2003)

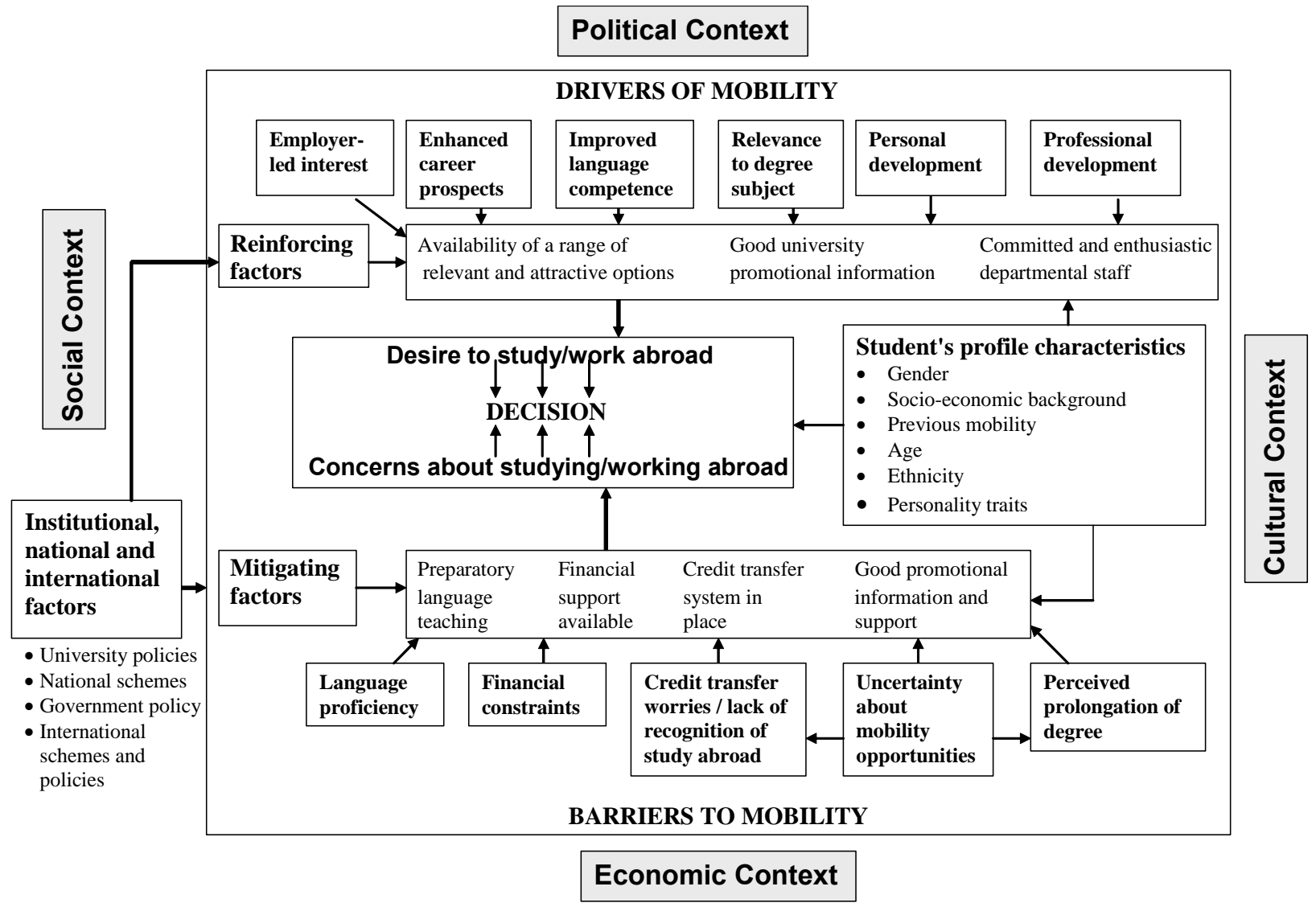

Figure 5 also indicates to policy makers a number of strategic interventions that can mitigate against the inhibiting factors and that can reinforce the desire for mobility (see Chapter 5). What the student survey revealed about future mobility aspirations is considered below..

\subsection{Future mobility}

Just over 40 per cent of all first-year students responding to the questionnaire definitely wanted to spend some time abroad during the remainder of their degree, and another 40 per cent were possibly interested in doing so (see Annex I, Table I16). What is significant is not only this openness to international mobility, but the forms of mobility in which students wished to engage. Most wanted to mix work and study (see Table 17). This is in contrast to the majority of final-year respondents who had been abroad on purely study-related visits.

Table 17: First-year students' ideal type of visit abroad

\begin{tabular}{lrr} 
Type of visit & No. & \% \\
\hline Study abroad & 79 & 16.5 \\
Work abroad & 76 & 15.8 \\
Mixture of both & 270 & 56.3 \\
Missing answers & 55 & 11.5 \\
\hline Total & $\mathbf{4 8 0}$ & $\mathbf{1 0 0 . 0}$ \\
\hline
\end{tabular}

Source: Authors' survey

One of the findings emerging from the questionnaire related to the feelings of final-year students who had not been abroad during their studies. Some 43 per cent of respondents regretted that they had not 
engaged in international student mobility. This seems a high proportion. On the face of it, this response reflects the potential unfulfilled desire of many students to travel for work or study. On the other hand, these are post-hoc views and may not reflect the reality of student choice.

One distinctive factor with the mobile group, compared with the non-movers, is that there are many more who said they would like to travel after graduation, and perhaps settle abroad in the future. Many stressed the fact that their university mobility had been influential in this decision.

'At the moment I'm planning to go and teach English in Japan next year. So I'm learning Japanese. I'm really interested in an international kind of career. And then this afternoon the careers talk ... was talking about working in the European Commission or within the European government. So, I'm planning to live abroad because most of these jobs are based in Brussels ... I mean, England is great, but l've realised that it's even better sometimes living abroad... and I really thrive on a more kind of challenging environment where you don't speak your mother language and where you have to interact with people from all over the world.' ( $G$ - $f$ - Italian Year abroad in Italy)

Many of the students who thought they would be mobile in the future intended to return to their studyabroad country, or to another one where the language they had learned at university was spoken:

'Ideally for me I would love to go to Cuba, I was in Cuba, and l'd love to go back ... either that or go to Mexico again, because I absolutely loved it; and it'll always be on the cards for me ... I would seriously reject a job in Northern Ireland for travelling purposes, you know, to go and live somewhere else ... I'm looking more on the Internet for jobs abroad as opposed to jobs here ... I suppose Spain, Spain is an option because it is close ...' (K-f - Languages - Year abroad in Mexico as language assistant)

Many of the non-movers also entertained thoughts of travelling abroad and of developing an international career. Yet a clear distinction was observed between movers and non-movers: the movers appeared to have 'more solid' career plans. It frequently came across in the interviews that the period abroad had served to clarify their career prospects in terms of life projects and further study - as these two extracts from a focus group illustrate:

'I was offered a job in Finland, and my partner now lives in Finland. I'm going to get some experience in England first, about six months to a year, and then by the time I finish, I'll probably apply for the Masters in Finland, and then work there because you can work while you're studying ... it is work-funded, so we have to find a job and then do the Masters ... it's part-time as well, so this way you can work during the Masters.' $(B-f-$ Nursing - Work placement in Finland)

'I'm planning to work a year, from when I finish here, but in the meantime I'm going to Finnish evening classes because I want to do the European Masters in Finland and there's the possibility to work there and get funded.' ( $B-f-$ Nursing - work placement in Finland)

Non-movers often said they regretted not having had mobility experiences:

'I think that it would be nice to live abroad at some stage in my life ... I sort of blame myself for not being able to give up everything and go out there, but I don't think I would have been able to do so ... I think it's always a bonus if you can speak something of a foreign language.' $(\mathrm{J}-\mathrm{m}-$ Geography) 
Such expressions of regret are evidence for taking the promotion and support of mobility more seriously. Quite apart from the language issue, which stretches back into the UK school curriculum debate, the question also arises as to when to inform students, and potential students, about mobility opportunities and benefits. Our interviews suggest that a more intense and widespread campaign of information and publicity is required, not only in the early months of a student's career in HE, but also in the final years of school and sixth-form education. 


\section{Synthesis and implications of findings}

\subsection{The eight questions answered}

\section{Question 1 - What is student mobility - how can it be defined?}

For the purposes of this study, ISM is defined as any form of mobility outside the UK which takes place during a student's time of registration at an HEl. Ideally the period of mobility should be long enough to have an impact on the student's appreciation of a foreign culture, and it should have some defined role within a student's learning experience. For many students, this includes the opportunity to apply skills in a foreign work context. However, definitional boundaries are not easy to draw, particularly with regard to short trips abroad, and especially when these do not have an explicitly educational purpose.

More broadly, ISM can be conceptualised as part of elite or high-skilled migration. It can also be viewed as part of youth mobility culture, motivated less by traditional economic migration factors (income, employment and so on) and more by educational, leisure and experiential factors. However, economics cannot be ignored: students may undertake study or work abroad in order to increase their competitiveness when seeking employment or as part of a desire to have an international career.

Question 2 - What trends can be identified in UK international student mobility and how do these compare with other countries?

Over the past 25 years there has been a marked upward trend in UK student migration rates to other countries. Inflows of foreign students to the UK have grown even faster, and these greatly outnumber UK students abroad.

The UK's student outflow is higher than that for some English-language countries like the US, but lower than the rates for other EU countries and the OECD as a whole. The US has been the most popular destination for UK students throughout the past 25 years. In recent years less than half of UK mobile students go to European destinations. The trend for UK outward Socrates-Erasmus mobility has been downwards since the mid-1990s, in contrast to most EU countries. However, Sweden and the Netherlands have started to follow the UK pattern.

\section{Question 3 - What are the main determining factors influencing students' mobility choices?}

Language is the first determining factor. For students majoring in foreign languages, a period of study or work abroad is generally compulsory. For most other students mobility is optional, and few choose that option. Mobile students are more likely to be female, to be 'young' (entering HE aged 18 or 19) and to come from more privileged backgrounds - as defined by parental education or occupation. Prior mobility - gap year, school trips abroad, foreign travel - has some influence too. Interviews suggest that the desire to travel, have a 'cultural experience' and promote 'self-development' are important 'personal drivers'. UK ethnic minorities are somewhat under-represented among mobile students, but there is evidence that 'non-UK white' (typically 'other European') students are more likely to be mobile than UK students.

Question 4 - To what extent is it useful to relate student mobility during the programme of study to prior mobility such as the gap year?

Questionnaire results show that the gap year, particularly if it involves time abroad, increases the propensity to be mobile during HE. Many respondents plan a gap year after graduating. Moving beyond the specific experience of the gap year, respondents who have a personal family history of travel 
abroad are more predisposed to be mobile as students. Such students can be described as building up 'mobility capital'.

Question 5 - What are perceived to be the main benefits of spending a period of time studying or working abroad?

Studying or working abroad brings multiple benefits. Students who have been abroad report significant personal, academic and professional 'pay-offs' from mobility. According to staff, students return from a foreign stay 'transformed'. Increased maturity, self-confidence, linguistic competence, better academic performance, cultural understanding and a clearer purpose in life are frequently remarked upon. Mobile students think they are more attractive to employers, but an employer survey would be necessary to verify this. Within HEIs, mobility schemes benefit the learning environment for all students, as returning students and incoming exchange students bring an added dimension to the classroom.

\section{Question 6 - What are the main barriers to international mobility for UK students?}

All available evidence points to two key constraints: finance and language. However, this finding should not be interpreted too simplistically. On the one hand, it is likely that, for individual students, the various barriers to mobility are closely interrelated, and some factors may be contingent on others. Moreover, each of the two main barriers has several ramifications. For instance, finance links importantly to parttime employment which imposes clear restrictions on students' ability to go abroad. Language, meanwhile, is obviously only relevant for certain destinations and mobility schemes. On the other hand, it needs to be remembered that important historical, cultural and economic forces shape the wider context in which mobility decisions are taken. Further research is needed on these contextual drivers of student mobility.

At the individual level, three other deterring factors were found to be important. Lack of information emerged as a key barrier - and one that can be rectified more easily than others. Academic and institutional barriers were also noted. Some students believed (often incorrectly) that going abroad would damage their degree prospects and delay their graduation. Some departments appeared to discourage mobility because of tight curricula or professional accreditation. Finally, less well-off students tend to regard mobility as an elite or middle-class phenomenon, or 'only for language students'.

\section{Question 7 - How important is UK students' foreign-language knowledge in conditioning their} propensity for international mobility?

As seen under questions 3 and 5 above, language is both a facilitating factor and a barrier for many students' mobility aspirations. Many students who might want (or have wanted) to be mobile blamed language shortcomings for their inability to turn their mobility aspirations into reality. At the same time, linguistic improvement is seen as one of the key benefits of studying or working abroad in a foreignlanguage environment.

Declining numbers of UK students on Erasmus exchanges in the last decade can be largely explained by the drop in the number of students on courses involving a language component. This is linked to falling student numbers taking public exams in language in secondary education. There was a general feeling among interviewees - students and staff alike - that much more should be done to promote language learning in schools.

Meanwhile, both students and HEls seem to be adapting their mobility behaviour and planning with more links to Anglophone countries, and a trend towards foreign work placements. 
Few institutions have a specific plan for outgoing student mobility, although such mobility does often feature as part of an institution's European policy statement or strategic plan for internationalisation. Mobility is always promoted in policy statements as 'positive' and 'desirable', and often deployed as a recruitment tool - with stress on attractive and exotic destinations. However, real commitment to expanding outward mobility and exchanges does not match the rhetoric. Instead the main focus is nearly always on recruiting high-fee overseas students.

The report found that high levels of Erasmus mobility are correlated with those HEls which are most research-active. This relationship may be indirect: well-resourced universities with strong research profiles can afford to maintain student exchanges and tend to attract more wealthy and cosmopolitan students who are more disposed to spend time abroad.

At the level of individual HEls, much depends on institutional and staff commitment to mobility efficient, knowledgeable administrators and advisors, and enthusiastic academics in individual departments.

\subsection{Policy implications}

The key findings listed above have many policy implications. Some of them are general issues and involve thinking 'outside the box' of the ISM model discussed in Chapter 4 (see Figure 5); others are more practical policy suggestions, and involve tweaking 'inside the box':

a. There is a need for more complete and regular national statistics on mobility. If such data can contain, or be matched with, students' biographical characteristics, a clearer idea can be gained about individual-level factors favouring or inhibiting mobility.

b. There is a need to recognise that students today are part of a 'mobility culture' which is different from that of 20 years ago, when many mobility schemes were first launched. National and institutional policies need to recognise that travel and mobility are now much more commonplace (and cheaper); but that, on the other hand, financial and linguistic constraints may inhibit traditional HE mobility experiences such as the standard 'European Year Abroad' of many language courses.

c. Existing mobility schemes are an imperfect match with demand. In particular there is underprovision of work or mixed study/work schemes which would respond more directly to students' (and perhaps employers') career expectations. Funded exchanges, overwhelmingly oriented to Europe, do not satisfy an increasing demand for study and placement schemes in North America, Australia and other centres of the global economy. Consideration should also be given to opening more mobility schemes with the global 'South'. This would help to bridge global economic and cultural divides and have positive development spin-offs. Allied to this, new exchanges could open up to reflect the changing ethnic heritage of the UK student population and their non-European linguistic resources. Careful market testing would be advisable for this.

d. HEls could be more proactive in promoting student mobility. It need not be sidelined by the priority to recruit high-fee overseas students. Student mobility could be more closely integrated into institutions' strategies for internationalisation, and efforts could be made for exchanges and placements to be more closely associated with international research collaboration. 
e. There is an urgent need to consider how linguistic ability at all levels in the UK education system could be improved. We recognise that this is a huge issue, which connects also to fundamental cultural attitudes within British society. Ideally, a major re-positioning of languages within the school curriculum is necessary. More emphasis could be placed on school exchanges with overseas countries.

f. Information and publicity about HE mobility schemes could be expanded, not only within the early years of HE courses, but also into schools and sixth-form colleges, so that (prospective) students know more about mobility opportunities before they apply for HE places.

g. Access to mobility needs to be broadened, so that social and institutional barriers are overcome. At present, many students are 'socially excluded' from mobility by virtue of their financial situation, family and class background, and linguistic limitations. Mobility opportunities should be opened up which overcome these factors of exclusion. 